LA WRENCE LIWEAMCAE NATIONAL LABDPATOAY
Metastability and Delta-Phase Retention in Plutonium Alloys

Final Report LDRD Project 01-ERD-029

A.J. Schwartz, K.J.M. Blobaum, C.R. Krenn, M.A. Wall, W.G. Wolfer, J.J. Haslam, K.T. Moore, J. Wong

February 17, 2004 
This document was prepared as an account of work sponsored by an agency of the United States Government. Neither the United States Government nor the University of California nor any of their employees, makes any warranty, express or implied, or assumes any legal liability or responsibility for the accuracy, completeness, or usefulness of any information, apparatus, product, or process disclosed, or represents that its use would not infringe privately owned rights. Reference herein to any specific commercial product, process, or service by trade name, trademark, manufacturer, or otherwise, does not necessarily constitute or imply its endorsement, recommendation, or favoring by the United States Government or the University of California. The views and opinions of authors expressed herein do not necessarily state or reflect those of the United States Government or the University of California, and shall not be used for advertising or product endorsement purposes.

This work was performed under the auspices of the U.S. Department of Energy by University of California, Lawrence Livermore National Laboratory under Contract W-7405-Eng-48. 


\title{
Metastability and Delta-Phase Retention in Plutonium Alloys \\ Final Report of LDRD Project 01-ERD-029
}

(February 17, 2004)

\author{
Principal Investigator: Adam J. Schwartz \\ Co-investigators: Kerri J. M. Blobaum, Christopher R. Krenn, \\ Mark A. Wall, Wilhelm G. Wolfer, Jeffery J. Haslam, \\ Kevin T. Moore and Joe Wong
}

Collaborator: Armen Khachaturyan, Rutgers University

Responsible Associate Directors: Bruce Goodwin (DNT) and Tomas Diaz de la Rubia (CMS)

\section{Summary}

The $\square$ to $\square$ ' phase transformation in $\mathrm{Pu}-\mathrm{Ga}$ alloys is intriguing for both scientific and technological reasons. On cooling, the ductile fcc -phase transforms martensitically to the brittle monoclinic $\square$ '-phase at approximately $-120^{\circ} \mathrm{C}$ (depending on composition). This exothermic transformation involves a $20 \%$ volume contraction and a significant increase in resistivity. The reversion of $\square$ ' to $\square$ involves a large temperature hysteresis beginning just above room temperature. In an attempt to better understand the underlying thermodynamics and kinetics responsible for these unusual features, we have investigated the $\square \leftrightarrow \square^{\prime}$ phase transformations in a Pu-0.6 wt\% Ga alloy using a combination of experimental and modeling techniques.

First, we induced, measured, and modeled the $\square \leftrightarrow \square$ ' martensitic transformation in a $0.6 \mathrm{wt} \% \mathrm{Pu}-\mathrm{Ga}$ alloy by a resistometry technique on a $2.8-\mathrm{mm}$ diameter disk sample. Our measurements of the resistance by a 4-probe technique were consistent with the expected resistance obtained from a finite-element analysis of the 4-point measurement of resistivity in our round disk configuration. Analysis by finite-element methods of postulated configurations of $\square$ ' particles within model $\square$ grains suggests that a considerable anisotropy in the resistivity may be obtained depending on the arrangement of the $\square^{\prime}$ lens shaped particles within the grains. The resistivity of these grains departs from the series resistance model and can lead to significant errors in the predicted amount of the $\square$ ' phase 
present in the microstructure. An underestimation of the amount of $\square$ ' in the sample by $15 \%$, or more, appears to be possible.

Both resistometry and differential scanning calorimetry (DSC) indicate that the martensite start temperature is $-120^{\circ} \mathrm{C}$ and the austenite start temperature is $35^{\circ} \mathrm{C}$. The heat of transformation is approximately $3 \mathrm{~kJ} / \mathrm{mole}$. During the $\square$ ' $\rightarrow \square$ reversion, "spikes" and "steps" are observed in DSC and resistometry scans, respectively. These spikes and steps are periodic, and their periodicity with respect to temperature does not vary with heating rate. With an appropriate annealing cycle, including a "rest" at room temperature, these spikes and steps can be reproduced through many thermal cycles of a single sample. A model of the residual stresses produced during the transformation can be used to understand some of the "burst-like" behavior.

Both relatively simple analytical models and more detailed finite-element and phasefield modeling are used to estimate the amount of thermal hysteresis that can arise from the large volume change during the $\square \leftrightarrow \square^{\prime}$ martensitic transformation. The analytical model produces good agreement with the experimental data available for a range of $\mathrm{Pu}-\mathrm{Ga}$ alloys. The finite-element model validated many of the assumptions used in the analytical model and was used to examine hysteresis in a palladium hydride system, which also has a large volume change, but has a more simple (and tractable) crystallography. We estimated the $\mathrm{Pd} / \mathrm{PdH}$ hysteresis using a finite-element model of the elastic and plastic works of multiple forward and reverse transformations and found reasonable agreement between finite-element estimates and experimental observations. We used a three-dimensional phase-field model to determine the effects of particle interactions, but for the isotropic dilation in the $\mathrm{Pd} / \mathrm{PdH}$ system, these interactions did not apparently have a significant effect.

Because accurate modeling of the phase transformation requires detailed understanding of the role of plastic flow during the transformation and of the crystallographic transformation path, transmission electron and optical microscopy were used to validate and improve our microstructural models. Using transmission electron microscopy (TEM), we found a significant increase in dislocation density in $\square$ near the $\square$ plates, which suggested that plastic deformation contributes to the accommodation of the $20 \%$ reduction in volume during the transformation. Analysis of a series of optical micrographs of partially transformed alloys suggested that the $\square \square$ habit plane is usually nearly perpendicular to $<111>$ Q. However, a small number of TEM observations supported a habit plane near $<112>$ or $<123>$, in agreement with earlier work.

In collaboration with Patrick Allen's LLNL LDRD project 01-ERD-030, extended xray absorption fine structure spectroscopy (EXAFS) was used to investigate the local 
atomic environment and the vibrational properties of plutonium and gallium atoms in the $\square$ ' and $\square$ phases of a Pu-0.6 wt\% Ga alloy. EXAFS spectra suggested that the $\mathrm{Ga}$ is substitutional for $\mathrm{Pu}$ atoms in both the $\square$ '-Pu and the $\square-\mathrm{Pu}$ structures. Since the $\square$ ' lattice has eight unique lattice sites, EXAFS was used to examine whether there was any preferential ordering of the $\mathrm{Ga}$ atoms either during the transformation or after a long (eight month) room temperature anneal. Analysis of the sample at eight months indicated no preferential ordering in either case, which suggests that the diffusion of the $\mathrm{Ga}$ in $\square$ '-Pu is very slow at ambient temperatures.

\section{Introduction}

The non-diffusive or displacive martensitic phase transformation remains one of the most challenging problems in physical metallurgy. To understand this phenomenon, one must simultaneously deal with thermodynamics and kinetics controlled by materials properties. The most extreme example of a martensitic phase transformation is found in $\mathrm{Pu}-\mathrm{Ga}$ and other $\square$-stabilized Pu-alloys. Here, the phase transformation results in a density change of approximately $20 \%$ assuring that stress and plastic accommodation play central roles in governing the details of the transformation. Additionally, accumulated radiolytic transmutations and radiation enhanced mass transport must be adequately considered. Kinetically dominated phase transformations where composition, microstructure, stress, and radiation effects all play important roles represent a challenging scientific issue with significant technological implications in a variety of defense, energy, and transportation systems.

Our objective was to develop the physical framework to describe and predict the important features of the transformation, such as martensite start temperature and width of the hysteresis. Our experimental approach involved parametric and microscopic studies of the martensite nucleation and hysteresis to understand the role of composition, microstructure, and plastic deformation. The experimental results allowed us to refine the two key aspects of the transformation model: nucleation and kinetics.

- -stabilized $\mathrm{Pu}-\mathrm{Ga}$ and $\mathrm{Pu}-\mathrm{Al}$ alloys are not stable materials at standard temperatures and pressures in the strict sense of equilibrium thermodynamics. These alloys are thermodynamically metastable and transform martensitically at low temperature into another metastable phase, monoclinic $\square$. This transformation occurs via a cooperative or synchronous shear of the lattice planes followed by atomic shuffles. The barrier for transformation is density accommodation through plastic deformation, but the driver is probably due to $5 \mathrm{f}$ electronic transitions and/or changes in phonon dispersion. Adler [1] systematically calculated the $\mathrm{Pu}-\mathrm{Al}$ and $\mathrm{Pu}-\mathrm{Ga}$ phase diagrams. These calculations were recently confirmed by Timofeeva [2] with several decades of experimental work. 
The eutectoid transformation now identified at $\sim 373 \mathrm{~K}$ means that $\square$-phase $\mathrm{Pu}$ is not in thermodynamic equilibrium at ambient temperatures and pressures, and if it were not for exceedingly slow kinetics, $\square$ would transform via a diffusional mechanism to $\square+\mathrm{Pu}_{3} \mathrm{Ga}$. The significance of this discovery is not so much the metastability of the $\square$-phase with respect to the eutectoid transformation, but now, for the first time, the true equilibrium phase diagram has been experimentally confirmed. Knowledge of the correct phase diagram will allow accurate calculations of the Gibbs free energy of the $\square$ - and $\square$-phases that are required for understanding and modeling the transformation to $\square$ '. However, the effects of aging and materials variability on the martensitic transformation cannot be modeled without further investigation. Composition, age, and microstructure will influence the martensitic transformation temperature, but to what degree is not clear. In light of the ongoing radiolytic mutations, continuing radiation damage accumulation, and the lack of true thermodynamic stability, it is important to undertake a program to understand the complex kinetic pathways for the $[-$ to $\square$ '-phase transformation. Only through a concentrated effort combining experiments and modeling will the nature of $\square$-phase retention in Pu binary alloys be understood and the consequences made deterministic.

Continuous cooling experiments focused on the phase transformation hysteresis loop lead to a deeper understanding of the relevant kinetics. The dilatometry results of S.S. Hecker et al [3] shown in Figure 1 reveal transformation temperatures of $188 \mathrm{~K}$ for the

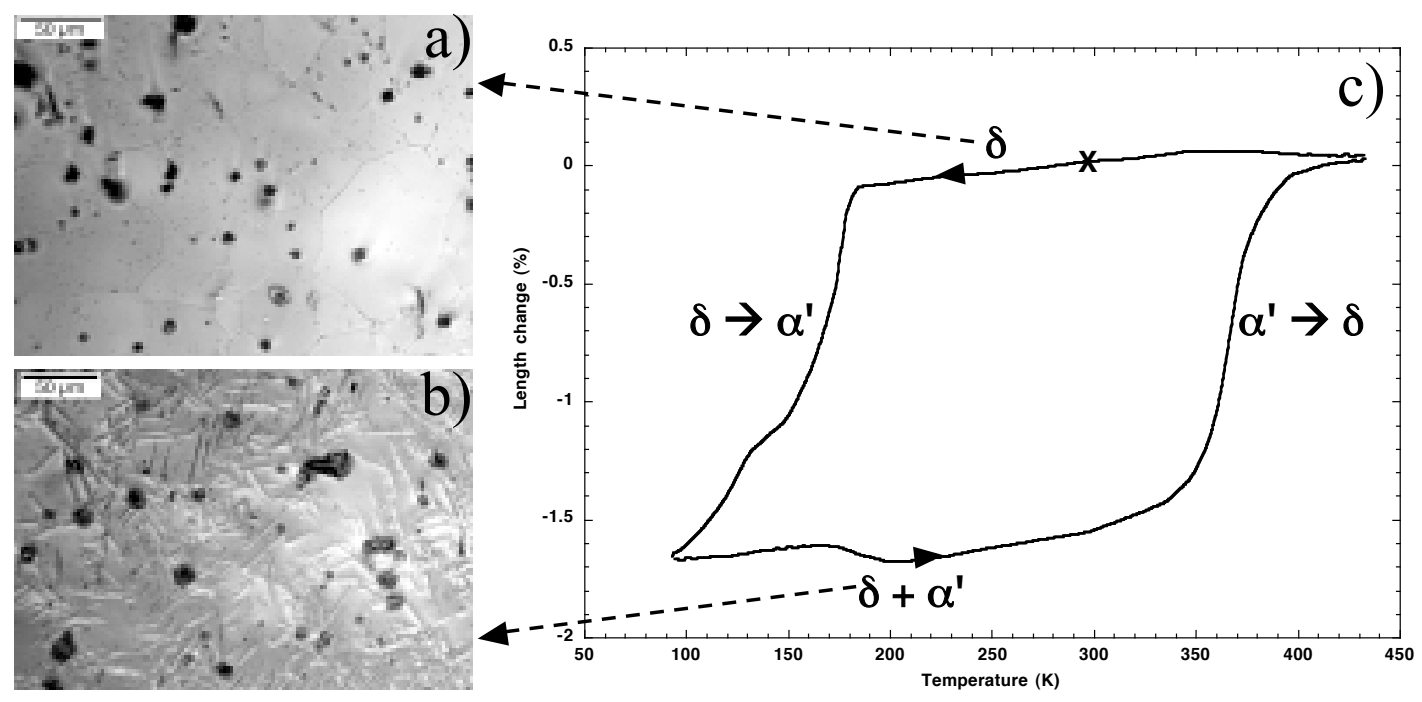

Figure 1: a) Optical micrograph of a $\square$-phase Pu-Ga alloy. b) Optical micrograph of a partially transformed Pu-Ga alloy ( $\square^{\prime}+\square$ phases). The $\square^{\prime}$ particles are thin plates. c) Dilatometry plot showing the length changes associated with the $\square \square$ ' transformations as a function of temperature. 
transition $\square \square \square^{\prime}$ on cooling from the $\square$ phase, and $348 \mathrm{~K}$ for the reverse transition $\square^{\prime} \square \square$. The temperature for the ideal thermodynamic transformation is somewhere between these extremes. Between the ideal and the actual transformation temperatures the material is in adoubly metastable state.

This report is organized along our major thrust areas: 1) Resistivity modeling is used to quantify experimental measurements of the transformation [4]. 2) The "burst like" characteristics of the $\square \square$ ' transformation are documented and analyzed [5]. 3) Continuum models are used to understand the large thermal hysteresis seen during the transformation [6]. 4) Transmission and optical micrography are used to validate and improve microstructural models of hysteresis and transformation crystallography [7]. And, 5) a brief account of how extended x-ray absorption fine structure spectroscopy (EXAFS) was used to investigate the local atomic environment and vibrational properties of plutonium and gallium atoms in the $\square$ ' and $\square$ phases of a $\mathrm{Pu}-0.6 \mathrm{wt} \% \mathrm{Ga}$ alloy is given [8]. Before presenting our conclusions and an analysis of what future work should be done, we summarize additional accomplishments, including our scientific papers and presentations, the development of new capabilities for plutonium science at LLNL and the recruitment of new lab personnel.

\section{Resistivity modeling}

\section{Introduction}

Resistometry is a reliable and sensitive method for monitoring the $\square \square$ ' phase transformations in $\mathrm{Pu}-\mathrm{Ga}$ alloys. At room temperature, the resistivities of the two phases differ by $\sim 25 \%$ and commercially available electronics can readily detect small changes $(\sim 0.1 \mu \square)$ in the resistance of the sample as it is cooled to form $\square$ '. Here, we used four-point probe (Kelvin probe) resistometry to monitor the formation and reversion of $\square$ ' as a thin Pu-Ga disc was thermally cycled between 70 and $500 \mathrm{~K}$. Prior to these experiments, however, it was important to determine the validity of the four-point probe technique with our sample geometry, and to analyze the effect of $\square$ ' particle orientation on the measured resistivity.

To determine the amount of $\square$ ' in a sample based on the measured resistivity, it is usually assumed that the total resistivity is a linear combination of the resistivities expected for the respective amounts of $\square$ ' and $\square$. Thus, the total resistivity is represented as:

$$
\square_{\text {total }}=x \square_{a^{\prime}}+(1 \square x) \square_{\square}
$$

where $\square_{\text {total }}$ is the measured resistivity (at some temperature, $T$ ), $x$ is the volume fraction of $\square$ ', and $\square_{\square^{\prime}}$ and $\square_{\square}$ are the resistivities of $\square$ ' and $\square$, respectively at temperature $T$. Such a 
(a)

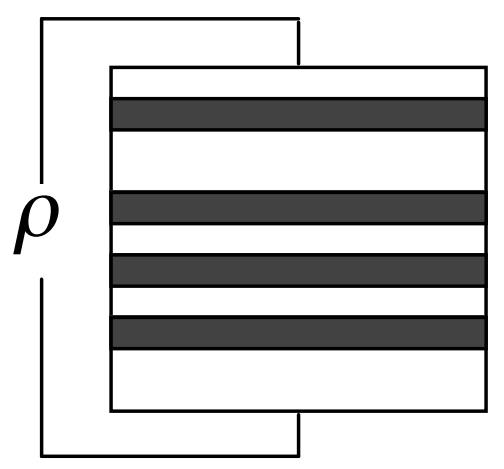

(b)

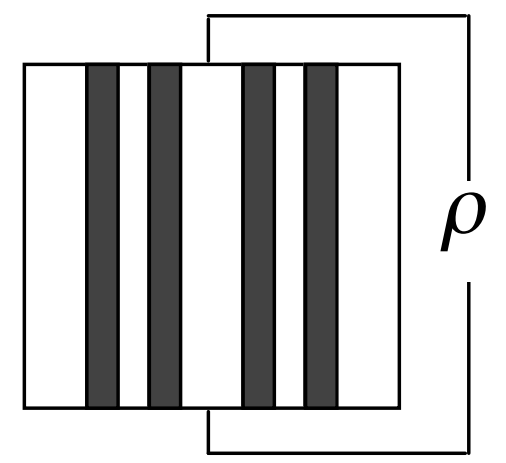

Figure 2: Series (a) and parallel (b) approximations for $\square$ ' particles in a $\square$ matrix. The black areas represent $\square$ ' and the white areas represent $\square$.

linear combination represents the microstructure as $\square$ ' and $\square$ "resistors" in series (Figure 2a). In reality, however, optical microscopy shows that the $\square$ ' phase typically exists as isolated, lens-shaped particles in the $\square$ matrix. Furthermore, the $\square$ ' particles tend to form in only a few orientations, or variants. Thus, the series model is likely to overestimate the amount of $\square$ ' in the sample. As a lower bound, we could assume that the $\square$ ' particles are arranged in parallel (Figure 2b). To evaluate which, if either, of these models best applies to the $\mathrm{Pu}-\mathrm{Ga}$ resistometry measurements, a two-dimensional analysis of the resistivity was performed using finite-element modeling (FEM). It should be noted that this analysis is applicable to resistometry measurements of any type of two-phase material, particularly where the second phase does not percolate through the grain or the sample.

\section{Experimental}

Resistometry experiments were performed in a large chamber at $\sim 10^{-5}$ torr. The chamber had glove ports which enabled samples to be mounted on the liquid helium cryostat inside. Samples could be held at a constant temperature or ramped between $\sim 4 \mathrm{~K}$ and $500 \mathrm{~K}$ as rapidly as $\sim 5 \mathrm{~K} / \mathrm{min}$, although most resistometry measurements were made with a heating rate of $1.5 \mathrm{~K} / \mathrm{min}$.

The Pu-0.6 wt\% Ga sample was a $2.8 \mu \mathrm{m}$ diameter TEM-sized disc with a thickness of approximately $500 \mu \mathrm{m}$. The four probes were $0.254 \mathrm{~mm}$ diameter copper wires which ran across the sample in parallel; the outer wires were the two current probes and the inner wires were used to sense the voltage drop across the sample.

As the sample was cooled from room temperature, $\square$ ' began to form and the resistivity of the sample increased (Figure 3). The resistivities of both $\square$ ' and $\square$ drop off sharply at low temperatures $(\sim 100 \mathrm{~K}$ for $\square$ ' and $\sim 150 \mathrm{~K}$ for $\square)$, and this drop was also observed in 


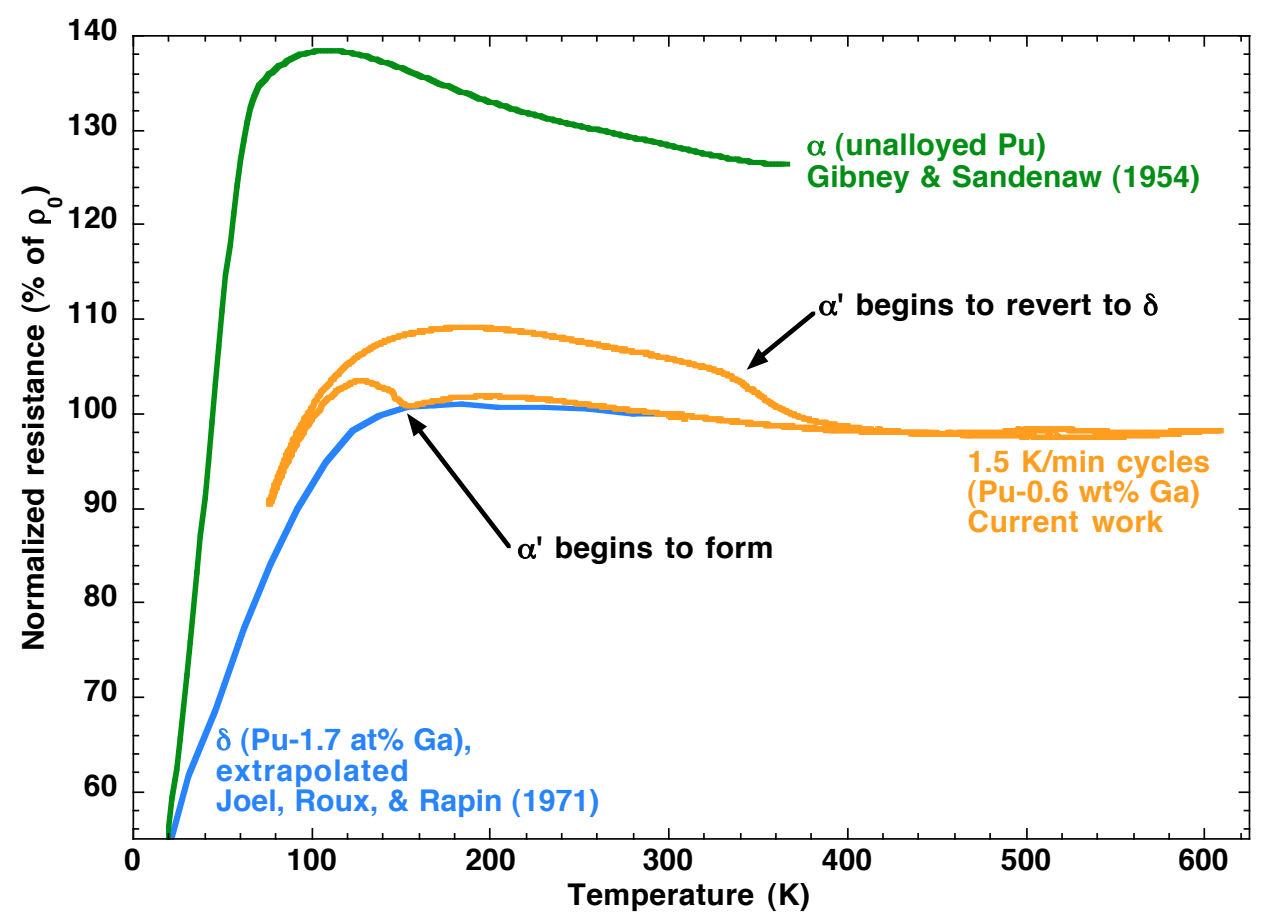

Figure 3: The top (green) and bottom (blue) curves are the resistivites of $\square[9]$ and $\square[10]$ plutonium, respectively, from the literature. Literature data for $\square$ ' resistivity was not available, so we assumed that it was similar to $\square$ in pure $\mathrm{Pu}$ [9]. For the $\square$ phase, the low temperature resistivity of a $\mathrm{Pu}-1.7$ at $\% \mathrm{Ga}$ alloy was extrapolated from room temperature [10]. The middle curve (orange) is data from our Pu- $0.6 \mathrm{wt} \% \mathrm{Ga}$ alloy. The increase in resistivity at $\sim 150 \mathrm{~K}$ corresponds to the beginning of transformation to $\square$ ' on cooling and the decrease in resistivity at $\sim 330 \mathrm{~K}$ is the reversion of $\square$ ' to $\square$

the resistometry measurements. When the sample was heated, the resistivity increased, but began to drop around $320 \mathrm{~K}$ as the $\square$ ' reverted to $\square$. It should be noted that the resistivity of the sample never attained the value of $\square$ ' because the sample only partially transformed to $\square$ '. Therefore, an understanding of how to calculate the fraction of $\square$ ' formed based on the resistivity of the sample was essential, and this is the work we describe below.

\section{Results and discussion}

\section{Finite-element analysis of the resistivity of a disc}

Finite-element modeling was first used to determine the applicability of the four-point probe technique to small disc-shaped specimens. The analysis indicated that the current spread rather uniformly between the inner (voltage) probes and through the sample thickness, with some perturbations at the locations of the current and voltage probes (Figure 4). Additionally, misalignment of the sample could cause a measurement error 

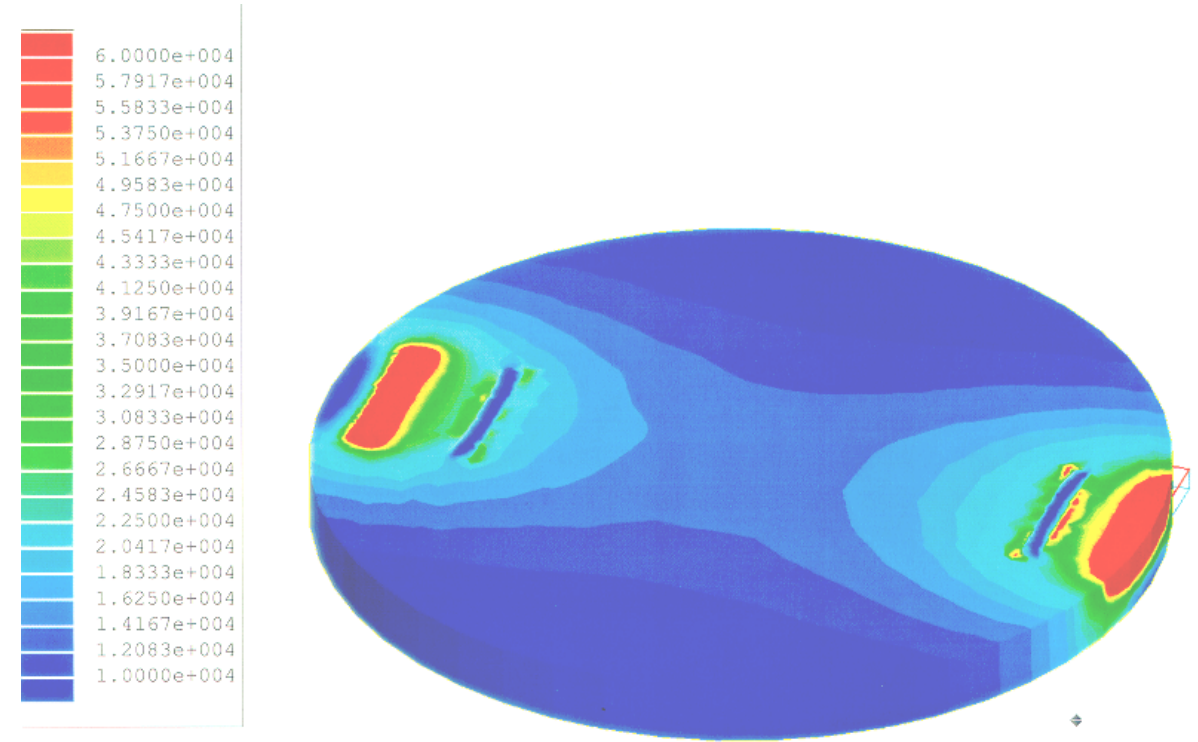

Figure 4: Finite element simulation of the current flow through the disc. Between the probes, the current flow is relatively uniform.

$\leq 2 \%$, but this was a relative error since the probes would not be expected to move during the experiments. Therefore, we concluded from these simulations that the four-point probe technique was suitable for use on our small plutonium alloy discs. Furthermore, this technique provided adequate sensitivity for monitoring the $\square^{\prime} / \square$ phase transformation during thermal cycling.

\section{Finite-element analysis of effects of particle orientation}

Because we intended to use resistometry to determine the volume fraction of $\square$ ' formed as a function of temperature, it was important to relate the fraction of $\square$ ' in a sample to the measured resistivity. Initial FEM simulations indicated that the resistivity could change considerably depending on the orientation and arrangement of $\square$ ' particles in the $\square$ matrix. Using finite-element techniques, the series and parallel models described earlier were analyzed using many configurations of lens-shaped $\square$ ' particles in a $\square$ matrix. It was determined that the series model may underestimate the amount of $\square$ ' in a sample by as much as $15 \%$. The parallel model, on the other hand, may overestimate the amount of $\square$ ' by a similar amount. A simple linear average of the series and parallel models provided the most accurate determination of the amount of $\square$ ' in a simulated sample. Therefore, finiteelement modeling demonstrated that the volume fraction of $\square$ ' in a sample can be determined using the series model or the parallel plate model with a linear correction.

\section{Comparison of the model to $x$-ray diffraction results}

Using a technique developed by Jackson and Pinkney [11], x-ray diffraction was used to estimate the amount of $\square$ ' in a sample; this result was compared to amount obtained using 
the corrected series model described above. Jackson and Pinkney's method utilized the relative intensities of peaks from a certain phase ( $\square$ ', in this case) and peaks from a reference material (such as the $\square$ matrix). A Pu- $0.6 \mathrm{wt} \% \mathrm{Ga}$ sample was analyzed using this technique and resistometry. X-ray diffraction showed that the sample contained $20.0 \mathrm{at} \%$ $\square$ '. Using the series model, resistometry indicated that the sample contained 17.7 at $\% \square$; the corrected series model gave a measurement of 20.8 at $\%$, which was in excellent agreement with the x-ray diffraction result. Therefore, we concluded that the corrected series model was a valid method for determining the amount of $\square$ ' in a sample based on resistometry measurements.

\section{"Burst-like" characteristics of the $\square \square$ ' phase transformation}

\section{Introduction}

In this section, we report two particularly interesting phenomena observed during thermal cycling experiments of a Pu- $0.6 \mathrm{wt} \% \mathrm{Ga}$ alloy. First, we show evidence for a "burst-like" transformation during the $\square$ ' $\rightarrow \square$ reversion on heating. DSC, resistometry, and dilatometry [12] all indicate that the transformation occurs in a "burst-like" progression as the temperature is increased. We analyze this data in terms of a simple thermodynamic model. Second, we describe an unexpected room temperature "annealing" requirement for reproducible transformation in a $\mathrm{Pu}-\mathrm{Ga}$ sample. A sample can be thermally cycled many times, but it must be "annealed" at room temperature after a high temperature anneal to obtain reproducible results.

\section{Experimental}

We investigated a Pu-0.6 wt\% Ga alloy using (DSC) and resistometry. This alloy was prepared by induction heating and was approximately two years old. Resistometry data was obtained with a four-point probe using discs with a diameter of $2.8 \mathrm{~mm}$ and a thickness of $0.1 \mathrm{~mm}$. The four probes were approximately $0.254 \mathrm{~mm}$ diameter copper wires that ran across the samples. Samples were kept under vacuum (typically $10^{-5}$ torr) and could be thermally cycled between $20 \mathrm{~K}$ and $700 \mathrm{~K}$ using a flow through helium cryostat. Heating rates as high as $5^{\circ} \mathrm{C} / \mathrm{min}$ were achieved, although most data was obtained during cycles at $1.5^{\circ} \mathrm{C} / \mathrm{min}$.

A Perkin-Elmer Diamond DSC equipped with a liquid nitrogen cooling system was used to thermally cycle samples between $-160^{\circ} \mathrm{C}$ and $350^{\circ} \mathrm{C}$. The pans were gold-plated stainless steel with a threaded lid that sealed against a gold-plated copper gasket, and were rated to withstand $150 \mathrm{~atm}$ at $400^{\circ} \mathrm{C}$. Although these pans were massive compared to the $\mathrm{Al}$ or $\mathrm{Cu}$ pans typically used for DSC experiments, they were chosen to provide sufficient containment. The purge gas used was a mixture of $90 \% \mathrm{Ne}$ and $10 \% \mathrm{He}$. This mixture 


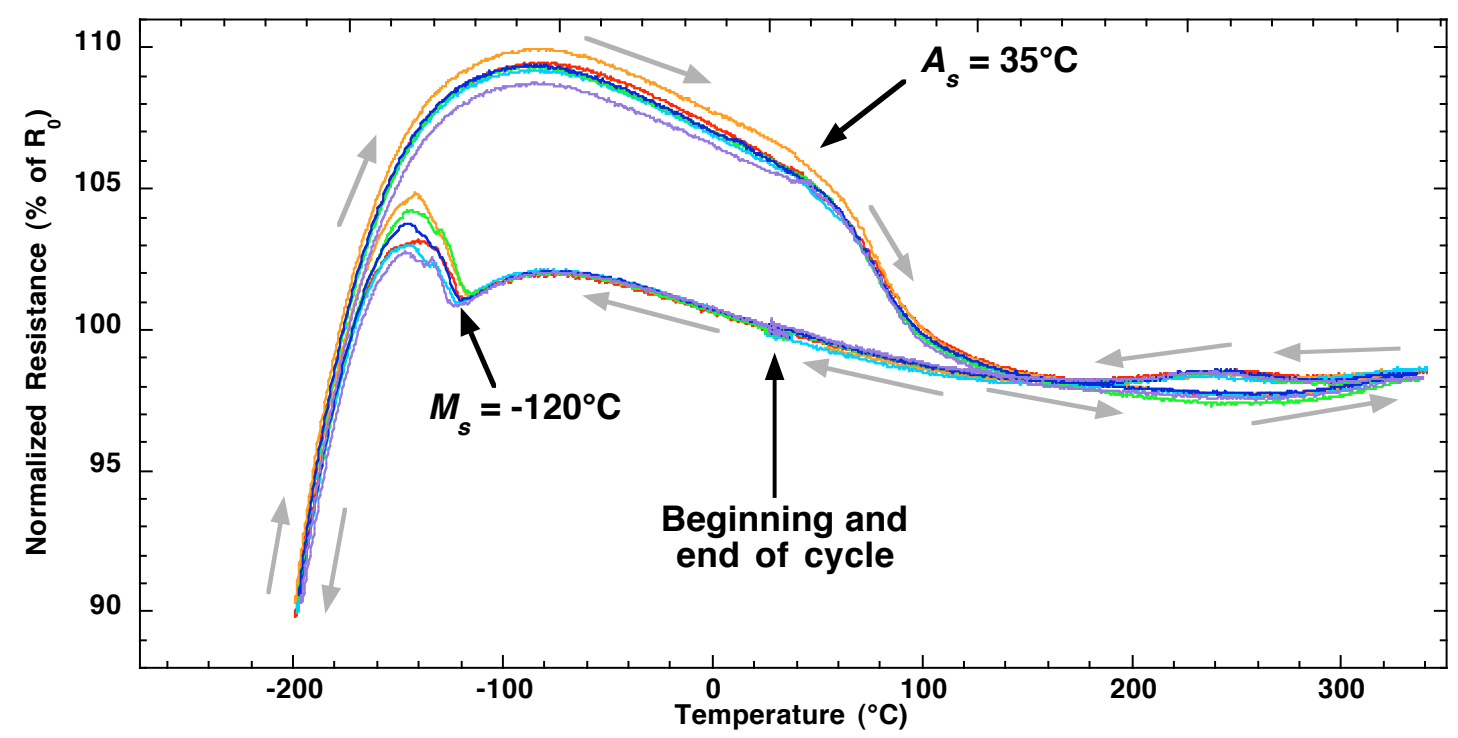

Figure 5: Resistometry data from thermal cycles at $1.5^{\circ} \mathrm{C} / \mathrm{min}$. The martensite start $\left(M_{S}\right)$ temperature is $-120^{\circ} \mathrm{C}$ and the austenite start temperature $\left(A_{S}\right)$ is $35^{\circ} \mathrm{C}$.

can be used from $-176^{\circ} \mathrm{C}$ to $585^{\circ} \mathrm{C}$, so problematic gas switching during thermal cycles was unnecessary [13].

\section{Results and Discussion}

\section{Transformation temperatures and heats of transformation}

Using resistometry and DSC, martensite start $\left(M_{S}\right)$ and austenite start $\left(A_{S}\right)$ temperatures of $-120^{\circ} \mathrm{C}$ and $35^{\circ} \mathrm{C}$, respectively, were measured. The data from the two techniques are in excellent agreement and the scans are reproducible within a few degrees. Figure 5 shows resistometry data for seven thermal cycles at $1.5^{\circ} \mathrm{C} / \mathrm{min}$. Each cycle had the following sequence: $25^{\circ} \mathrm{C} \rightarrow-200^{\circ} \mathrm{C} \rightarrow 350^{\circ} \mathrm{C} \rightarrow 25^{\circ} \mathrm{C}$. The marked increase in resistivity at $\sim$ $120^{\circ} \mathrm{C}$ signals the beginning of $\square$ ' phase formation. Likewise, the decrease in resistivity beginning around $35^{\circ} \mathrm{C}$ corresponds to reversion to the $\square$ phase. In the DSC, the cycle is similar, except the lower limit is $-160^{\circ} \mathrm{C}$. Figures $6 \mathrm{a}$ and $6 \mathrm{~b}$ show the cooling and heating portions of a single DSC thermal cycle at $20^{\circ} \mathrm{C} / \mathrm{min}$. The $\square \rightarrow \square^{\prime}$ transformation is marked by an exothermic peak with an onset of $-121^{\circ} \mathrm{C}$; the $\square$ ' $\rightarrow \square$ reversion is an endotherm with an onset of $31^{\circ} \mathrm{C}$. Figure $6 \mathrm{~b}$ also shows an additional endotherm corresponding to $\square$ $\rightarrow \square$ transformation. Prior to the first DSC experiment, the sample was annealed into the $\square+\square$ phase field where Ga rapidly diffuses out of the $\square$ phase. Upon cooling, the Ga-lean regions transform to the $\square, \square$ and $\square$ phases, and these transformations ultimately result in pre-existing $\square$ phase remaining at room temperature. After several thermal cycles, this peak disappeared. 
a)
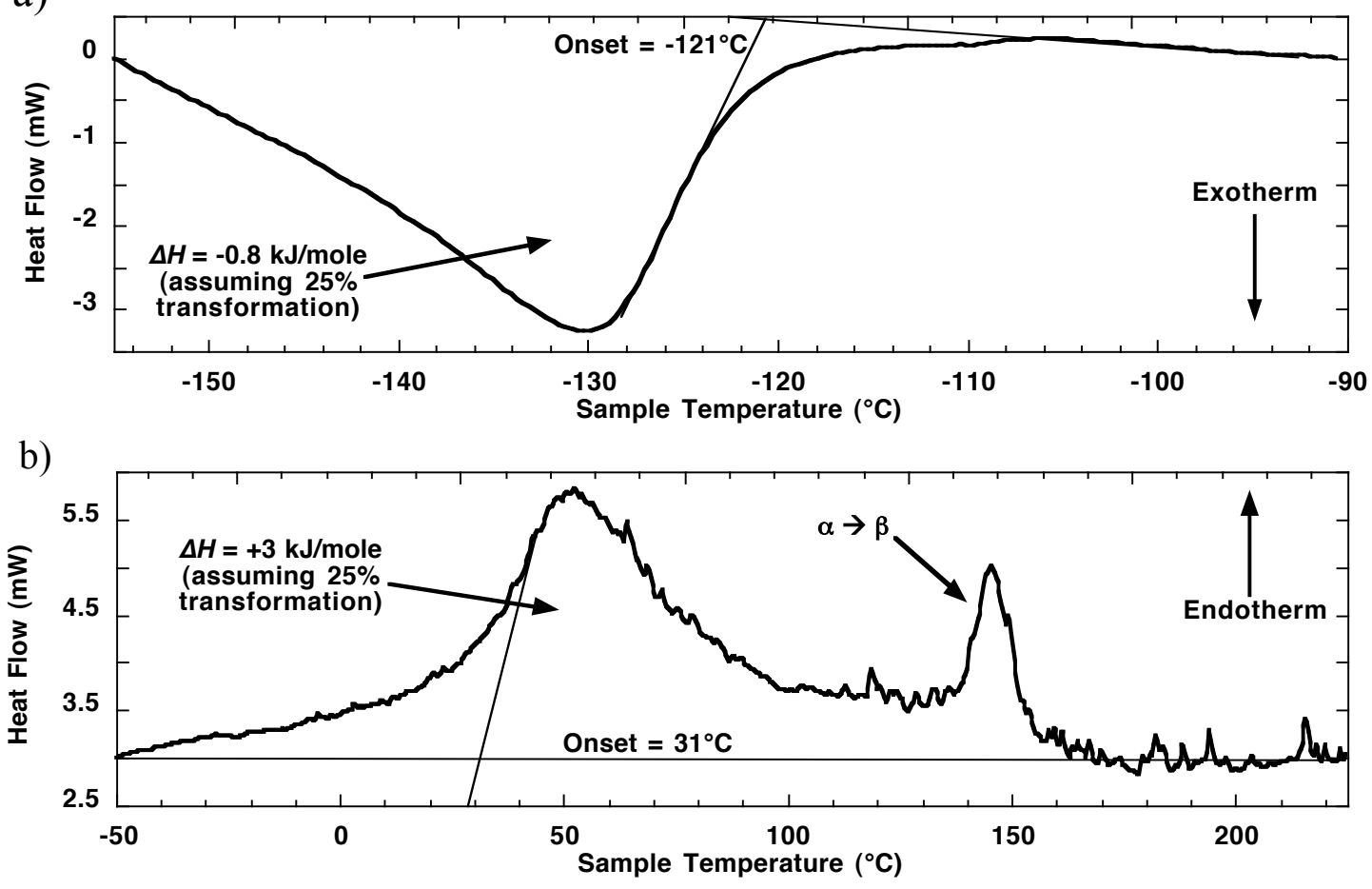

Figure 6: Cooling (a) and heating (b) portions of a DSC scan $\left(20^{\circ} \mathrm{C} / \mathrm{min}\right)$. The exothermic $\square \rightarrow \square$ ' transformation has an onset of $-121^{\circ} \mathrm{C}$ and $\Delta H=-0.8 \mathrm{~kJ} / \mathrm{mole}$. The onset of the reversion to $\square$ is $31^{\circ} \mathrm{C}$ and $\Delta H=+3 \mathrm{~kJ} /$ mole.

Using resistivity data from the literature, we calculate the amount of transformation to the $\square$ ' phase and then use this to estimate the heats of transformation from the DSC data. Resistivity data for $\square$ ' is not available, so data for $\square$ are extrapolated to higher temperatures [9]. For the $\mathrm{Q}$ phase, data for a $\mathrm{Pu}-1.7 \mathrm{at} \% \mathrm{Ga}(0.5 \mathrm{wt} \%)$ alloy are extrapolated to low temperatures [10]. From this data, we estimate that the maximum amount of transformation to the $\square$ ' phase is $25 \%$. Thus, the areas of the DSC peaks (Figures $6 \mathrm{a}$ and $6 \mathrm{~b}$ ) correspond to only $25 \%$ of the total heat of transformation for each reaction. Total heats of transformation $\left(\Delta H_{t}\right)$ are estimated to be $-0.77 \mathrm{~kJ} / \mathrm{mole}$ for $\square \rightarrow \square$ ' and $3 \mathrm{~kJ} / \mathrm{mole}$. For $\square^{\prime} \rightarrow \square$. The measured value of $\Delta H_{t}\left(\square \rightarrow \square^{\prime}\right)$ is believed to be a lower bound, because it is unlikely that the $\square \rightarrow \square^{\prime}$ transformation proceeded to completion on cooling within the temperature range of the DSC peak. Furthermore, additional transformation on heating is observed in our resistometry cycles and by other authors [3]. In the DSC, however, this additional transformation may be too slow to be discriminated from the baseline. Even though we measure values of $\Delta H_{t}\left(\square \rightarrow \square\right.$ ') far from the equilibrium temperature $\left(T_{0}\right)$, we still expect the absolute values of $\Delta H_{t}\left(\square \rightarrow \square^{\prime}\right)$ and $\Delta H_{t}\left(\square^{\prime} \rightarrow \square\right)$ to be approximately 
equal. We therefore suggest that $\Delta H_{t}(\square \rightarrow \square$ ') lies closer to $-3 \mathrm{~kJ} / \mathrm{mole}$ because the transformation volume and the DSC peak area are better defined for the reverse transformation. (We note that because the observed heat flow includes a contribution from the storage and release of elastic energy during the transformation and because finite-element modeling suggests that less elastic energy is released during $\square^{\prime}$ reversion than during $\square^{\prime}$ formation [6], $\Delta H_{t}(\square \rightarrow \square$ ') is actually expected to be somewhat greater than $\Delta H_{t}\left(\square^{\prime} \rightarrow \square\right.$ ). This difference, however, is expected to be small.)

\section{Burst transformations}

A series of "spikes" and "steps" corresponding to the $\square$ ' $\rightarrow \square$ reversion are seen in DSC and resistometry thermal cycles, respectively. In both cases, the spikes or steps become more pronounced as the heating rate decreases. This is particularly evident in Figure 7, which shows DSC traces at four heating rates ranging from $1.5^{\circ} \mathrm{C} / \mathrm{min}$ to $20^{\circ} \mathrm{C} / \mathrm{min}$. In these scans, the "spikes" appear to be superimposed on a broad endothermic peak. Similar "spikes" have been observed in DSC scans of Pu-Ga alloys by other groups $[12,14]$. Close inspection of resistometry data between $\sim 25^{\circ} \mathrm{C}$ and $125^{\circ} \mathrm{C}$ also reveals a series of "steps." In differentiated resistometry data, the peaks in this region look distinctly different from the data surrounding this temperature range. Dilatometry data for a $\mathrm{Pu}-0.6 \mathrm{wt} \% \mathrm{Ga}$ alloy published by Mitchell, et al [12] also show a series of "steps" attributed to the $\square$ ' $\rightarrow \square$ reversion. These "spikes" and "steps" observed by DSC, resistometry, and dilatometry suggest that the $\square$ ' $\rightarrow \square$ reversion occurs in a series of thermally

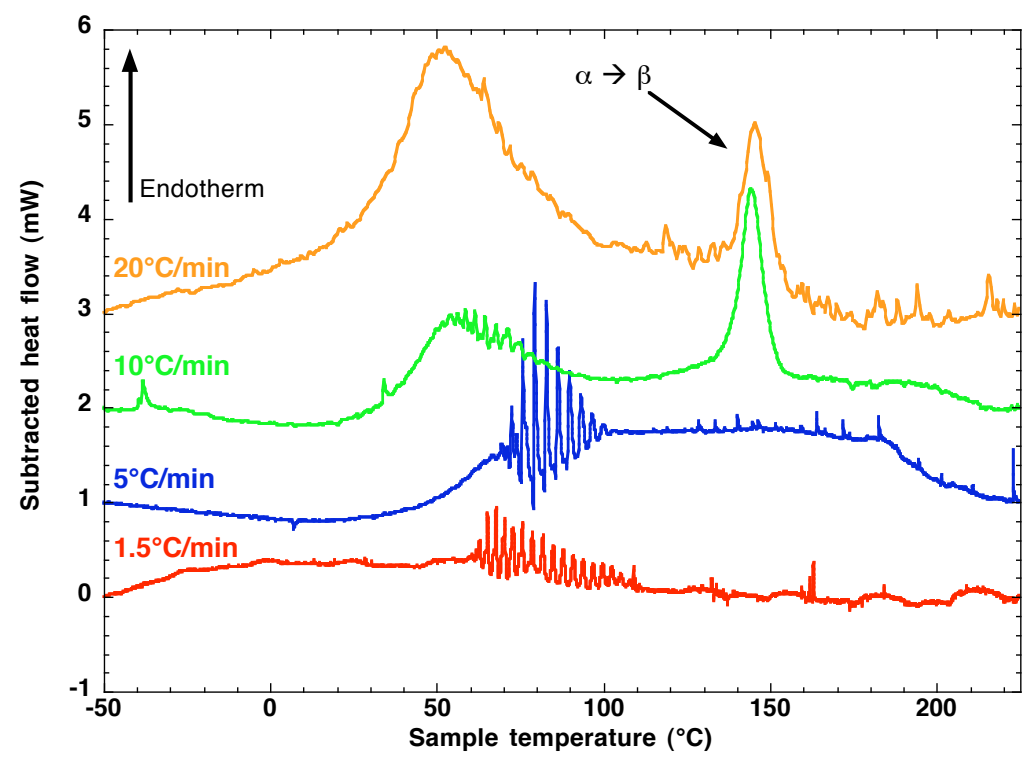

Figure 7: DSC heating scans at $1.5,5,10$, and $20^{\circ} \mathrm{C} / \mathrm{min}$. Scans were offset along the $y$ axis for clarity. Distinct "spikes" corresponding to the $\square$ ' $\rightarrow \square$ reversion were observed at the 3 slowest rates. 
activated bursts.

The temperature spacing between adjacent peaks in our DSC and resistivity data has been measured and found to be essentially constant, regardless of heating rate. Thus, the bursts are periodic with respect to temperature in this alloy. To compare our data with burst behavior reported in the literature, distances $\left(\square\right.$, in $\left.{ }^{\circ} \mathrm{C}\right)$ between peaks are measured. The "tallest" peak is arbitrarily identified as peak " 0 ." Figure 8 shows data from our DSC and resistometry scans along with DSC data (Pu-0.56 wt\% Ga) from Kitching [14] and dilatometry data $(\mathrm{Pu}-0.5 \mathrm{wt} \% \mathrm{Ga}$ and $\mathrm{Pu}-0.6 \mathrm{wt} \% \mathrm{Ga})$ from Mitchell, et al [12]. For the $0.6 \mathrm{wt} \%$ alloy, the period is fairly constant for all heating rates and characterization techniques. The other alloys show slightly different periods. These data suggest that $\square$ may be related to composition, microstructure, impurities, homogeneity, or other factors.

\section{Stress analysis}

Finite-element calculations of the elastic and plastic works of transformation also indicate that residual stresses resulting from plastic deformation may be responsible for the spikes and steps observed with DSC, resistometry, and dilatometry. Residual stresses in the regions surrounding $\square$ ' particles which have reverted back to the $\square$ phase are a result of plasticity during the transformation. Figure 9 is a finite-element analysis map of the stress distribution in the region of a reverted $\square$ ' particle. At the tip of the particle, the stresses aid further reversion. In regions perpendicular to the particle (along the long axis), the stresses retard further transformation. Thus, these regions may require additional heating to surmount the energy barrier for transformation. As a sample is heated during DSC, resistometry, or dilatometry, we will expect some reversion of martensite particles occurring readily at fairly low temperatures. This reversion, however, sets up a stress state that makes it difficult for further reversion. Thus, additional reversion requires more

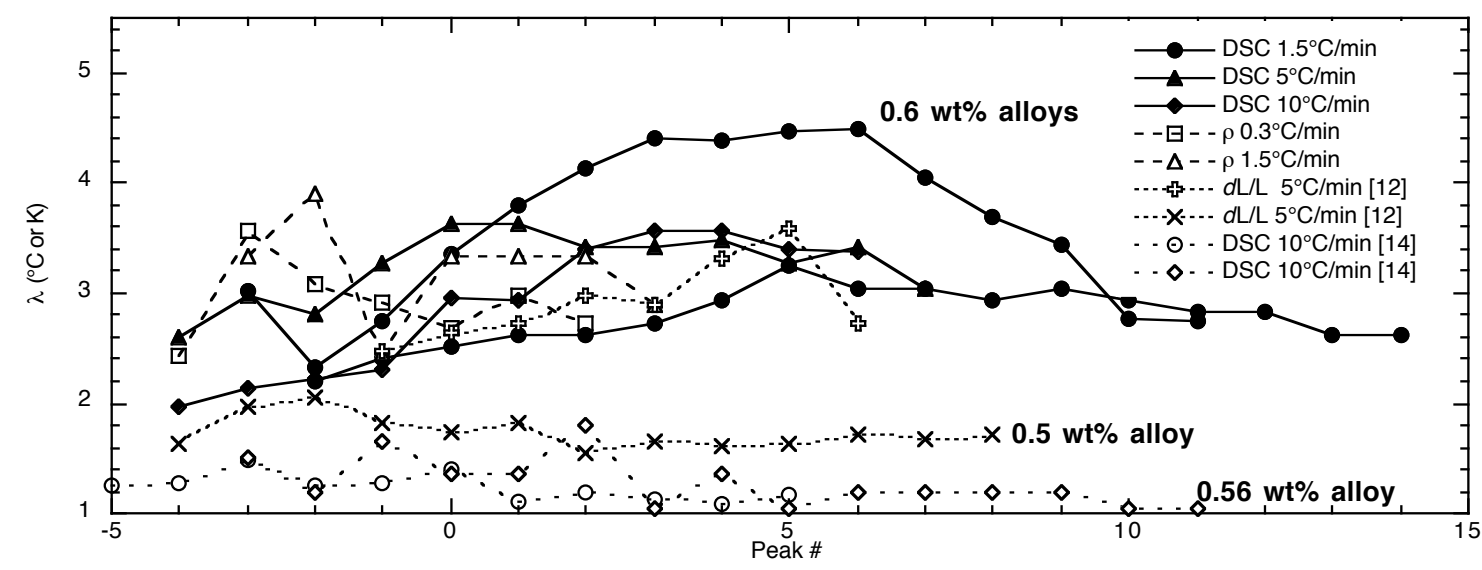

Figure 8: Periodicity of "bursts" observed with DSC (this study), resistometry ( $\square$ ) (this study), dilatometry ( $d \mathrm{~L} / \mathrm{L})[12]$, and DSC [14]. 


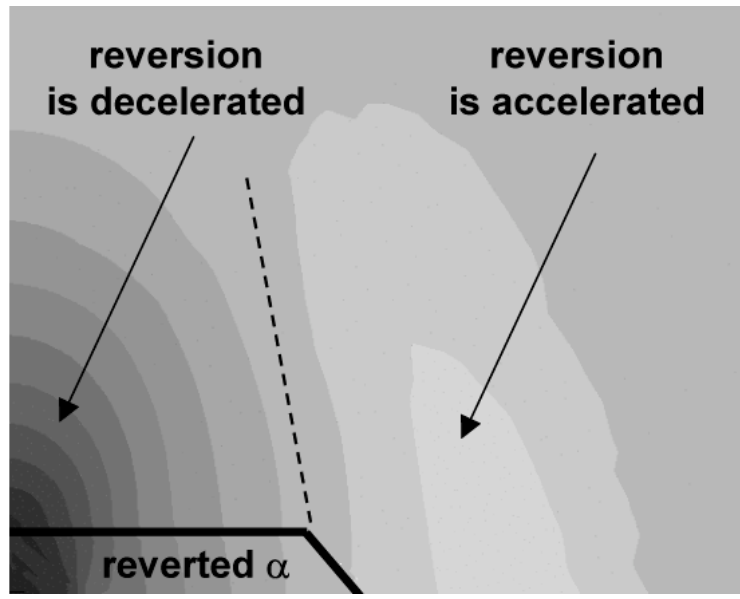

Figure 9: Finite-element map of the normal stress field surrounding an $\square$ ' particle which has reverted to the $\square$-phase. The stress field accelerates reversion in front of the reverted particle and decelerates the reversion in regions perpendicular to it. The zero-stress contour is dashed.

heat, and we observe another "burst" of transformation. This cycle will continue until the temperature is sufficient to revert all of the $\square$ ' particles back to the $\square$ phase.

\section{Room temperature "annealing”}

Thermal cycling experiments without a prior "rest" or "hold" at room temperature do not exhibit evidence of transformation to $\square$ ' on cooling. Specifically, the DSC trace does not show a peak above the background. Upon heating, however, a peak corresponding to the $\square^{\prime} \rightarrow \square$ reversion provides evidence that some transformation occurs during cooling. The amount of reversion (and, hence, transformation), however, is smaller than the amount observed after a room temperature "rest." Thus, we found that a single sample could be thermally cycled many times with the same amount of transformation during each cycle, provided that it is annealed at $375^{\circ}$ for 8 hours, and then allowed to "rest" at room temperature for at least six hours.

To investigate this behavior further, we hold samples at room temperature for various lengths of time between annealing at $375^{\circ} \mathrm{C}$ and the next thermal cycle. The time at room temperature ranges from 0 to 87 hours. Between each experimental run, we perform a control run to verify that the sample returns to the same starting point each time. In the control runs, the room temperature hold is 12 hours. Each experimental and control run is followed by a thermal cycle. Figure 10 shows the $\square$ ' $\rightarrow \square$ reversion portion of the DSC thermal scans. (Note that "spikes" are not apparent in these scans because they are done at $20^{\circ} \mathrm{C} / \mathrm{min}$.) The extent of the transformation is calculated from the area under the DSC peak. From Figure 10, it is clear that as the time held at room temperature decreases, the amount of transformation also decreases. It is important to note that the control runs 


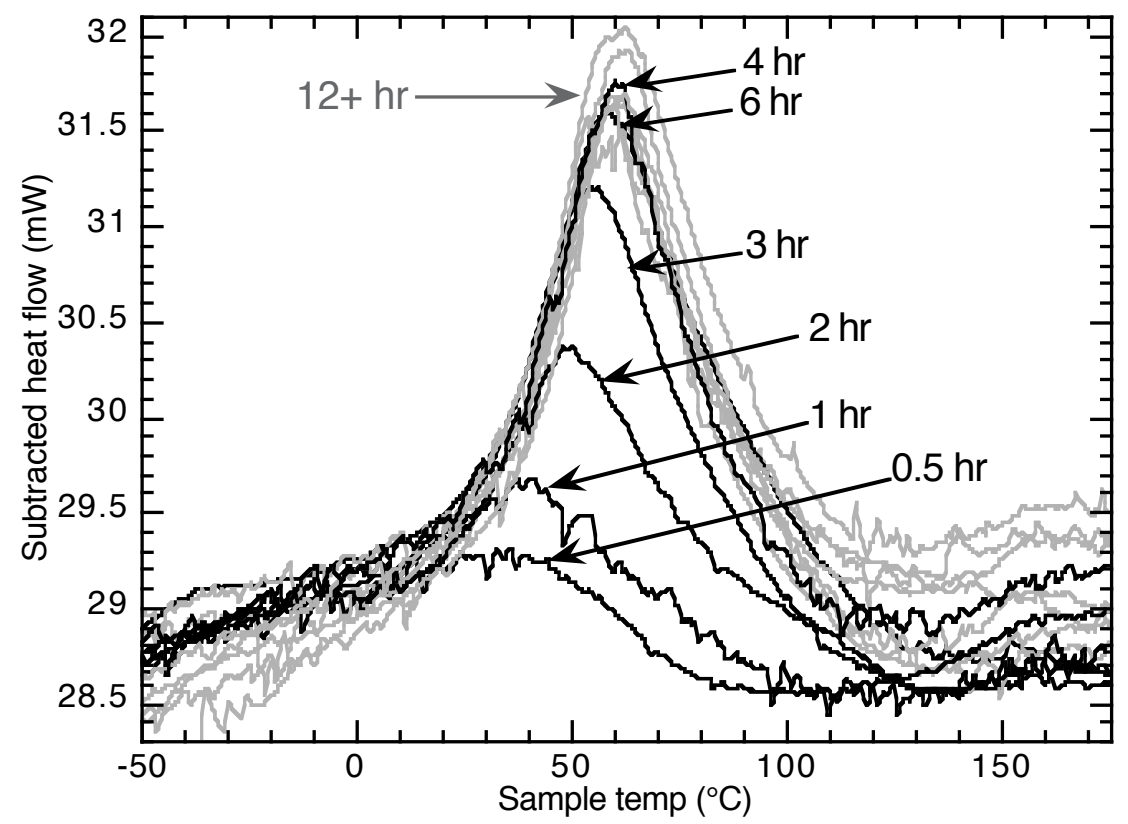

Figure 10: DSC scans (heating portions) of samples allowed to "rest" at room temperature for various lengths of time. The amount of transformation is related to the length of time the sample "rests" at room temperature, but this effect appears to saturate after about 4-6 hours.

show exceptional reproducibility, attesting to the fact that a satisfactory annealing sequence can be implemented which allows a sample to be cycled many times. It is also interesting to note in Figure 10 that the 4 and 6 hour holds have similar areas to the 12 hour holds. The areas of all the peaks shown in Figure 10, as well as some additional long holds, are plotted in Figure 11. Note that the left $y$-axis corresponds to the exothermic $\square \rightarrow \square$ ' transformation where the areas are negative. In this case, the amount of transformation increases as the numbers become more negative (larger absolute value). The opposite is true for the right $y$-axis which corresponds to the endothermic $\square$ ' $\rightarrow \square$ reversion. Figure 11 quantitatively indicates that the effect of the room temperature hold saturates after approximately 6 hours.

An open question remains as to why this room temperature hold is essential for transformation in a sample thermally cycled many times. At room temperature, radiation damage may accumulate in the sample [15]. This damage may provide nucleation sites for $\square$ ' particles, thus enabling the transformation at low temperatures. A second possibility is that $\square$ ' growth at low temperatures is dependent on the prior diffusional growth of small $\square$ nuclei at intermediate temperatures below the eutectoid of $97^{\circ} \mathrm{C}$ [16]. These nuclei would not grow to any significant size because of the elastic constraint of the $\square$ matrix, 


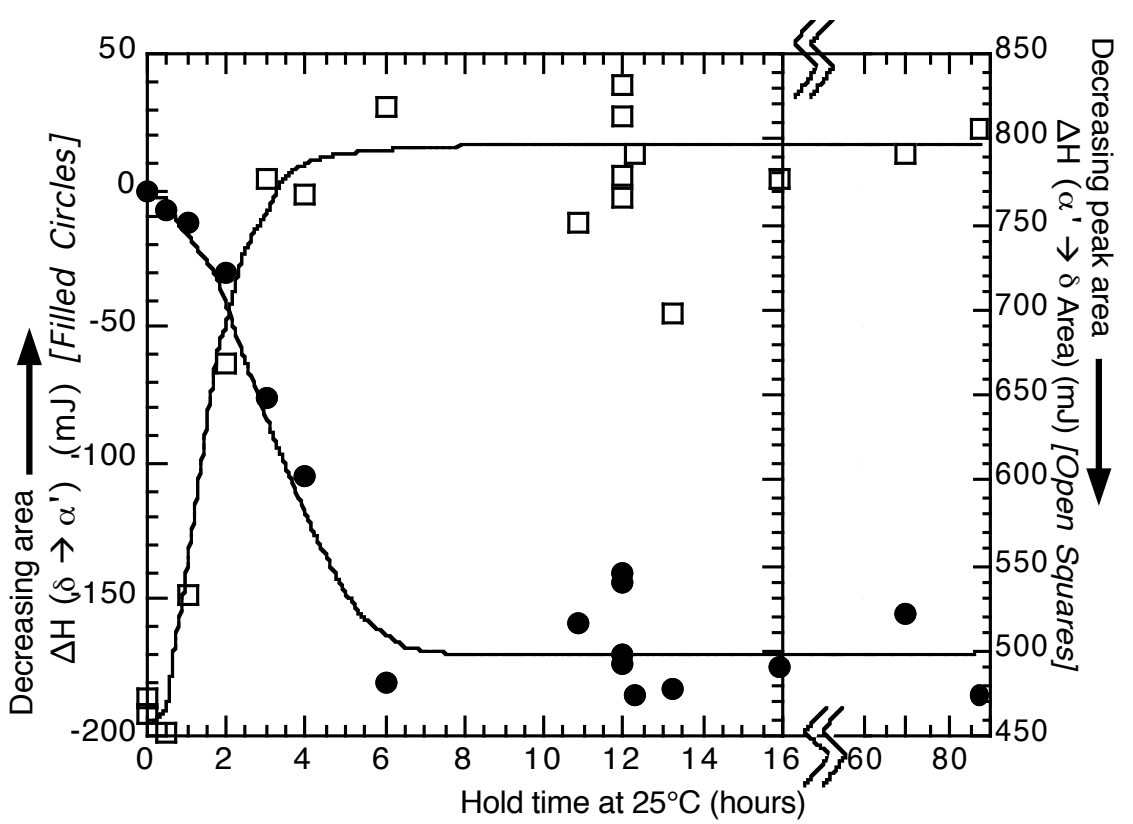

Figure 11: Measured $\Delta H$ for transformation of $\square$ ' to $\square$ (left $y$-axis) and reversion of $\square$ ' to $\square$ (right $y$-axis). $\Delta H$ for the reaction is the area of the DSC peak (Figure 10). Note that $\Delta H_{t}$ $(\square \rightarrow \square$ ') values are negative for this exothermic reaction. Thus, peak areas decrease toward the top of this $y$-axis. The opposite is true for the endothermic $\square$ ' $\rightarrow \square$ reversion.

but they could form near defects such as grain boundaries where the elastic constraint is reduced. Formation of these nuclei is not thermodynamically possible above the eutectoid temperature and is kinetically constrained below room temperature.

\section{Analytic model of transformation hysteresis}

In the first year of this LDRD project, we developed a simple analytical model of hysteresis. Our hypothesis was that the hysteresis was entirely due to plastic dissipation that was induced by the large volume change between $\square$ and $\square$ ':

$$
\square G^{\square \square} \square\left(T, x_{G a}\right)= \pm \square W_{\text {plastic }}
$$

Undercooling ( $-\square G$ ) below the equilibrium transformation temperature was required to overcome the plastic dissipation, and superheating $(+\square G)$ above the equilibrium transformation temperature was required for the reversion. The plastic dissipation work was estimated by the following formula:

$$
\square W_{\text {plastic }}=\frac{2}{3} \square_{u t s} \square V^{\square \square},
$$




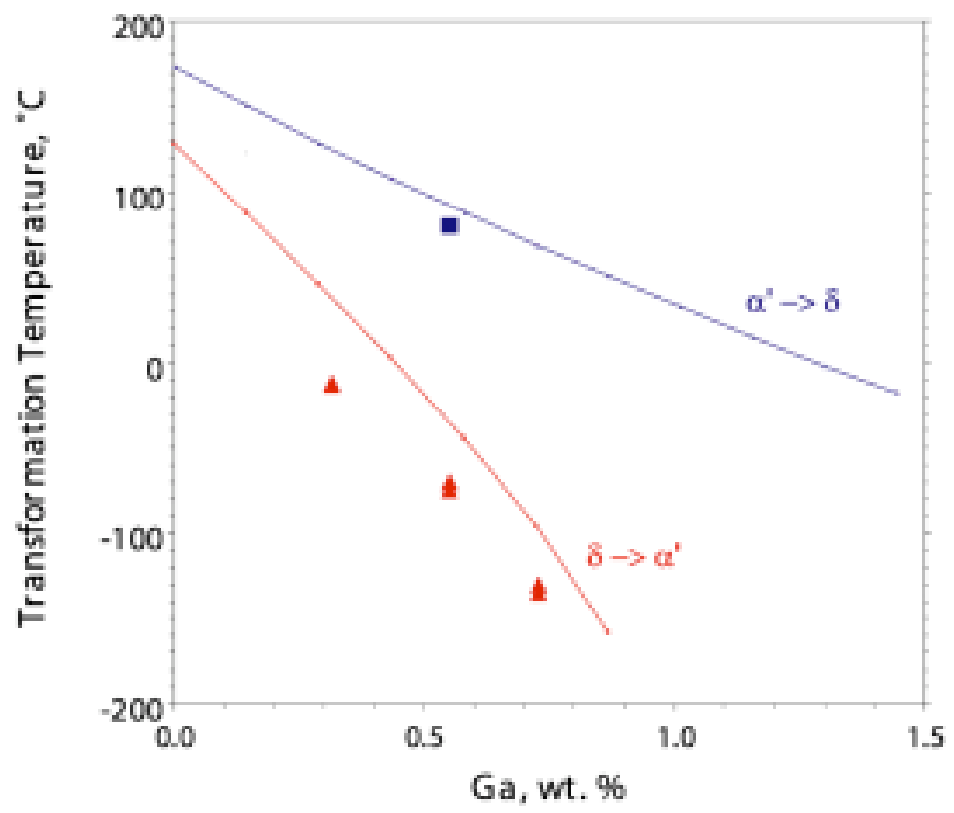

Figure 12: A comparison of our analytic model for the martensite start and austenite reversion temperatures (lower and upper lines) with the available data for $\mathrm{Pu}-\mathrm{Ga}$ alloys (triangles and squares).

where $\square_{u t s}$ is the ultimate tensile strength, and $\square V^{\square \square}$ is the volume change between $\square$ and $\square$ '. (The assumption of a planar transformation front results in the factor of $2 / 3$ ). The Gibb's free energy change is written as a sum of two terms:

$$
\square G^{\square \square \square}\left(T, x_{G a}\right)=\square \bar{G}^{\square \square \square}\left(T, x_{G a}\right)+\square G^{\square \square \square(}\left(T, x_{G a}\right),
$$

where $\square \bar{G}^{\square \square}\left(T, x_{G a}\right)$ is the regular solution model developed by Adler [1], while $\square G^{\square \square \square(}\left(T, x_{G a}\right)$ is a new term. This term accounts for the difference in coherency strain energies between the $\square$ and $\square$ ' phases, and it is determined from the experimentally measured lattice parameters of these two phases [3]. (This estimate of misfit energy was also comparable to recent results of electronic structure calculations [17].) Finally, $\square_{u t s}\left(T, x_{G a}\right)$ was taken from the 1967 Plutonium Handbook [18].

Figure 12 compares the results of this model with Los Alamos data [19]. 


\section{Finite-element and phase-field modeling of transformation hysteresis}

\section{Introduction}

The $\square$ to $\square$ ' phase transformation in Pu-Ga alloys has an unusually large volume change. This volume change results in large stresses that require plastic accommodation. However, the crystallography of this transformation is quite complex, and still not completely understood (See the next section for more details). Hysteresis in metal hydride systems was studied initially because, as in the plutonium transformation, the large volume change between the metal and hydride can induce significant plastic deformation [20]. At the same time, the crystallography of the transformation is much more simple (an isotropic dilation in the case of $\mathrm{PdH}$ ), which makes modeling and analysis of these systems relatively simple.

Although Schwarz and Khachaturyan [21] have developed a purely elastic model of hysteresis for coherent two-phase systems, a greater number of authors have included plastic dissipation in their analytical models of the hysteresis in metal-hydride systems [22-25]. Leitch and Shi have coupled a careful analysis of the thermodynamics of metalhydride hysteresis with a set of finite-element calculations to quantify the magnitudes of elastic energy storage and plastic dissipation during the transformation [26]. From a set of finite-element calculations of a single cycle of precipitation and dissolution of an isolated hydride particle, they concluded that the hysteresis was largely due to plastic dissipation but that there was also a contribution from an irreversible storage of elastic energy during the transformation.

In this work we extend the work of Leitch and co-workers [26, 27] by using finiteelement techniques to look at multiple cycles of precipitation and dissolution of palladium-hydride particles in a palladium matrix and find reasonable agreement between the elastic and plastic hysteresis calculated and that which is experimentally observed. Our modeling also predicts that the hysteresis of the first precipitation and dissolution cycle is always higher than the hysteresis of subsequent cycles. In addition, we use a threedimensional phase-field model to determine the effects of particle interactions. For the isotropic dilation in the $\mathrm{Pd} / \mathrm{PdH}$ system, these interactions are not found to have a significant effect.

\section{Method}

First, we review a thermodynamic model of the metal-hydride transformation that incorporates both internal elastic energy and plastic dissipation. Second, we evaluate the elastic energy and plastic work terms using a two-dimensional axisymmetric finite-element 
model. Finally, we examine the dynamics of particle growth and interactions using a threedimensional microelastic phase-field model [28].

\section{Thermodynamic model}

Leitch and Shi [26] wrote the free energy change of the transformation of the $\square$ hydride phase from the hydrogen-metal solid solution $\square$ as a sum of four terms:

$$
\square G_{\square \square \square}=\square G_{\square \square \square}^{\text {chem }}+\square G_{\square \square \square}^{\text {elastic }}+\square G_{\square \square \square}^{\text {plastic }}+\square G_{\square \square \square}^{\text {surface }},
$$

where $\square G_{\square \square \square}^{\text {chem }}$ is the free energy change during the formation of unconstrained $\square, \square G_{\square \square \square}^{\text {elastic }}$ and $\square G_{\square \square}^{\text {surface }}$ are the elastic and surface energies required to accommodate the $\square \square \square$ volume change and the creation of $\square / \square$ interfacial area. $\square G_{\square \square \square}^{\text {plastic }}$ is not strictly speaking a "free energy", but it represents the heat dissipated during the plastic accommodation process. The free energy change during the reverse transformation has the same form:

$$
\square G_{\square \square \square}=\square G_{\square \square \square}^{\text {chem }}+\square G_{\square \square \square}^{\text {elastic }}+\square G_{\square \square \square}^{\text {plastic }}+\square G_{\square \square \square}^{\text {surface }} .
$$

Because the $\square / \square$ interfacial area that is created during precipitation is destroyed during dissolution,

$$
\square G_{\square \square \square}^{\text {surface }}=\square \square G_{\square \square \square}^{\text {surface }},
$$

but no assumptions are made about the relationship between $\square G_{\square \square \square}^{\text {plastic }}$ and $\square G_{\square \square \square}^{\text {plastic }}$ or between $\square G_{\square \square \square}^{\text {elastic }}$ and $\square G_{\square \square \square}^{\text {elastic }}$. Assuming that kinetic constraints on the transformation are small (which is reasonable given the high diffusivities of hydrogen and the high stresses driving plasticity), transformation will begin when the total $\square G$ is less than zero. Assuming that $\square G^{\text {chem }}$ is a function of the temperature $T$ and the partial pressure of hydrogen $P_{H}$ but that the elastic and plastic works are insensitive to the temperature and pressure of the transformation, we can define an excess chemical work of transformation that is proportional to the overpressure or the undercooling that is required to drive the transformation:

$$
\square G_{\square \square \square}^{\text {excess }}=\square G_{\square \square \square}^{\text {elastic }}+\square G_{\square \square \square}^{\text {plastic }}+\square G_{\square \square \square}^{\text {surface }} \text {. }
$$

Because the elastic and plastic works are proportional to volume but the surface energy is proportional to interfacial area, in the quasi-static limit this reduces to the following:

$$
\begin{aligned}
& \square G_{\square \square \square}^{\text {excess }}=\square G_{\square \square \square}^{\text {elastic }}+\square G_{\square \square \square}^{\text {plastic }} \text {, and } \\
& \square G_{\square \square \square}^{\text {excess }}=\square\left(\square G_{\square \square \square}^{\text {elastic }}+\square G_{\square \square \square}^{\text {plastic }}\right) .
\end{aligned}
$$

The energetic width of the hysteresis is then given by

$$
\square G_{\square \square \square}^{\text {excess }} \square \square G_{\square \square \square}^{\text {excess }}=\square G_{\square \square \square}^{\text {elastic }}+\square G_{\square \square \square}^{\text {plastic }}+\square G_{\square \square \square}^{\text {elastic }}+\square G_{\square \square \square}^{\text {plastic }},
$$


and the experimental pressure hysteresis can be determined from the following:

$$
\square G_{\square \square \square}^{\text {excess }} \square \square G_{\square \square \square}^{\text {excess }}=\square \frac{1}{2}\left(c^{\square} \square c^{\square}\right) R T \log \left(\frac{P_{A}}{P_{B}}\right),
$$

where $c^{\square}$ and $c^{\square}$ are the equilibrium concentrations of hydrogen in the $\square$ and $\square$ phases, and $P_{A}$ and $P_{B}$ are the absorption and desorption pressures [29]. To evaluate $\square G_{\square \square \square}^{\text {elastic }}$, $\square G_{\square \square \square}^{\text {elastic }}, \square G_{\square \square \square}^{\text {plastic }}$ and $\square G_{\square \square \square}^{\text {plastic }}$ we will use finite-element techniques.

\section{Finite-element model}

As in the work of Leitch and coworkers [26, 27], we use the thermal expansion of a misfitting particle embedded in an elastic-plastic matrix to model the precipitation of an isolated hydride particle. Although the morphology and deformation of PdH particles can be quite complex [20,30], we use a spherical geometry and an elastic/perfectly plastic matrix for our initial studies. (Leitch and coworkers have analyzed the influence of particle aspect ratio, but in their calculations, the energy difference between a spherical particle and one with a elastically preferred aspect ratio of $\sim 0.75$ is not great $[26,27]$.) At the equilibrium compositions for $\square \mathrm{Pd}$ and $\square \mathrm{PdH}$ at $300 \mathrm{~K}$ [31], the elastic properties of the particle and matrix are taken as an isotropic average of the properties for Pd [32] and $\mathrm{PdH}$ [33], giving a Young's modulus of $128 \mathrm{GPa}$ and a Poisson's ratio of 0.3835 . The $\mathrm{Q} / \square$ volume mismatch at $300 \mathrm{~K}$ of $10.57 \%$ is taken from Feenstra et al. [34]. Experimental upper and lower bounds for the flow stress of Pd $(52 \& 317 \mathrm{MPa})$ are taken from yield strength measurements by Goods and Guthrie [35]. For comparative purposes, recent calculations of the ideal strength of Pd (2.4 GPa) are taken as an absolute upper bound to the flow stress [36]. Using the finite-element code ABAQUS [37], a volume ratio of bulk to particle of 999, a mesh of 75 elements for the particle and 2000 for the bulk, and a loading rate of $5 \%$ of the total misfit strain per time step is sufficient to resolve the elastic and plastic work of the transformation to within $\sim 1 \%$ of the available analytical solutions [38]. Table 1 compares the finite-element and analytical solutions of the work required for forward transformation with a variety of flow stresses. Table 1 also shows that the small strain approximations that are implicit in the analytical solutions give results that are 5$6 \%$ smaller than the finite-strain finite-element solutions. Because the finite-strain corrections are significant, we chose to use these solutions in the remainder of this paper.

\section{Phase-field model}

The finite-element calculations give us results for the precipitation of a single isolated hydride particle surrounded by an effectively infinite metal matrix. However, in real solidstate reactions, there are multiple interacting precipitates, and most reactions consume a large fraction (if not all) of the matrix. The most convenient and efficient technique to 


\begin{tabular}{|c|c|c|}
\hline & $\begin{array}{c}\text { Elastic } \\
\text { Work }\left(\mathrm{MPa}^{*}\right) \\
\end{array}$ & $\begin{array}{c}\text { Plastic } \\
\text { Work (MPa) }\end{array}$ \\
\hline \multicolumn{3}{|l|}{ Pure Elastic $\left(\square_{\mathrm{y}}=\square \mathrm{MPa}\right)$} \\
\hline Analytical Model** & 240.78 & - \\
\hline FEM (small strain approximation) & 240.88 & - \\
\hline FEM (finite strain calculation) & 252.67 & - \\
\hline \multicolumn{3}{|l|}{ Elastic + Plastic $\left(\square_{\mathrm{y}}=52 \mathrm{MPa}\right)$} \\
\hline Analytical Model & 3.53 & 13.88 \\
\hline FEM (small strain approximation) & 3.54 & 13.77 \\
\hline FEM (finite strain calculation) & 3.74 & 14.48 \\
\hline \multicolumn{3}{|l|}{ Elastic + Plastic $\left(\square_{\mathrm{y}}=317 \mathrm{MPa}\right)$} \\
\hline FEM (finite strain calculation) & 22.25 & 48.65 \\
\hline \multicolumn{3}{|l|}{ Elastic + Plastic $\left(\square_{y}=2400 \mathrm{MPa}\right)$} \\
\hline FEM (finite strain calculation) & 142.3 & 71.6 \\
\hline
\end{tabular}

Table 1: Comparison of the results of an analytical model [38] and finite-element calculations of the elastic and plastic works of transformation for the precipitation of a $\mathrm{PdH}$ particle in an elastic/perfectly plastic Pd matrix given four different flow stresses of the matrix:.

model microstructural evolution during a phase transformation is the phase-field method. Originally implemented by Kobayashi in two dimensions to model the complex branching growth of dendrite crystals during solidification [39], the technique was extended by Wang and Khachaturyan to handle in three dimensions the elastic energy contributions important to solid-state martensitic transformations [28]. In this work we adapt a phasefield code developed by Jin, Artemev and Khachaturyan [40] for martensitic transformations to the specific problem of the growth of palladium hydride particles in a palladium matrix. We do not explicitly model the diffusion of hydrogen through the matrix but assume that it is fast relative to the rate at which hydrogen is added to the system.

Because the formation of the $\square$ phase does not change the symmetry of the lattice-it is still cubic but has a larger crystal lattice parameter - the crystal lattice rearrangement in the $\square \square \square$ transformation produces one rather than several orientation variants. Thus the material microstructure can be characterized by a single order parameter, $\square(\boldsymbol{r})$, and we can use a one-dimensional linear time-dependent Ginzburg-Landau kinetic equation,

$$
\frac{\partial \square(\mathbf{r}, t)}{\partial t}=L \frac{\square F^{\text {total }}}{\square(\mathbf{r}, t)},
$$


to model the microstructural evolution. $L$ is the kinetic coefficient, and the total energy of the system $F^{\text {total }}$ is written as a sum of chemical $F^{\text {chemical }}$, elastic $F^{\text {strain }}$, and surface or gradient terms, $F^{\text {surface }}$ :

$$
F^{\text {total }}(\square(r))=F^{\text {chemical }}+F^{\text {strain }}+F^{\text {surface }} .
$$

The local chemical energy is taken to be a simple fourth order polynomial:

$$
F^{\text {chemical }}=\square\left[\square f\left(a \square^{2}+b \square^{3}+c \square^{4}\right)\right] d^{3} r,
$$

where $-\square f$ is the driving force for hydride formation, and $a, b$ and $c$ are chosen so that $F^{\text {chemical }}$ is locally minimal at $\square=\{0,1\}$, corresponding to the metal matrix and metal hydride phases respectively. To run simulations at a given volume fraction of hydride $\square_{t \text { arg } e}$, we define $\square f$ as a linear function of the current volume fraction $\square$,

$$
\square f=d\left(\square_{t \arg e t} \square \square\right),
$$

and $d$ is a constant. With a sufficiently large value of $d$, the system will converge to within an arbitrary distance of $\square_{t \text { arget }}$.

Within the scope of this project, it was not possible to implement an elastic-plastic accommodation model within the numerical phase-field frameworks that were available, so the strain energy $F^{\text {strain }}$ is solved elastically for a purely dilatational misfit using Fourier integration of the closed form solutions developed by Khachaturyan and co-workers $[41,42]$. Details of the computational implementation are available in the papers by Wang and Khachaturyan and by Jin et al. [28, 40].

Finally, the gradient or surface energy is given by

$$
F^{\text {surface }}=\frac{k}{2} \square(\square \square)^{2} d^{3} r
$$

where $k$ is the gradient coefficient.

For the simulations in this paper, the microstructure is discretized on a periodic $64 \times 64 \times 64$ grid, and the external applied stress on the system is fixed to be zero. Hydride particles are nucleated by the insertion of small seeds with diffuse interfaces at random positions, and the misfit of the hydride particles is a purely dilatational strain.

\section{Results and discussion}

\section{Finite-element model}

Figure 13 shows finite-element results for the evolution of total elastic energy and incremental plastic work during several cycles of hydriding and de-hydriding, with a matrix flow stress of $317 \mathrm{MPa}$ and no work hardening. As Leitch and Shi [26] have observed, there is a residual stored elastic energy in the system after one cycle. However, in subse- 


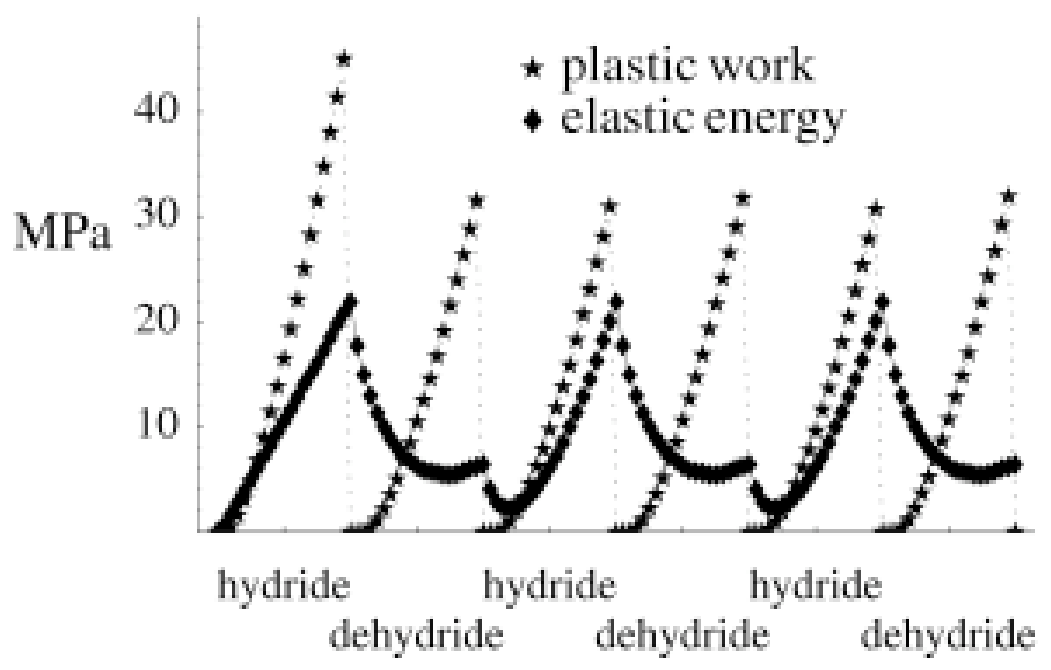

Figure 13: Finite-element solutions for the elastic energy (stars) and incremental plastic work (diamonds) as a palladium hydride particle expands and contracts in the lattice. In this example, the flow stress is $317 \mathrm{MPa}$ and represents a fully work hardened material.

quent cycles, the total elastic energy is conserved. Interestingly, the incremental plastic work is also significantly larger for the first $\square \square \square$ hydriding step, but then it is roughly constant for subsequent hydriding and de-hydriding steps. We believe the initial excess plastic work is necessary to develop the initial plastic zone.

Figure 14 plots schematic hysteresis curves using the excess chemical work of transformation defined by equations 5 and 6 for several different flow stresses. Both the initial hysteresis (outer loops) and the steady-state hysteresis (lower loops) are shown. Table 2 lists the width of the hysteresis predicted from equation 7 and compares it with two sets of experimental data $[29,43]$. The results in Table 2 are also qualitatively consistent with the experimental observations of Lambert and Gates who saw an $\sim 8 \%$ decrease in hysteresis between the first and second cycles [44]. While our model predicts a greater decrease if a reasonable value of flow stress is used, this may be because of our neglect of work hardening.

Although Figure 14 shows that the excess work required for transformation increases with increasing flow stress, the hysteresis is minimized at very small and at very high flow stresses. As Wolfer and Guthrie have previously noted in a purely plastic analysis of hysteresis in $\mathrm{PdH}$ systems [25], this implies that there are two effective flow stresses that are consistent with a given magnitude of hysteresis and that there is a roughly parabolic relationship between flow stress and hysteresis. Because Wolfer and Guthrie observed that hysteresis decreased with increasing radiation damage and because radiation damage is expected to increase flow stress, they concluded that the physically plausible 


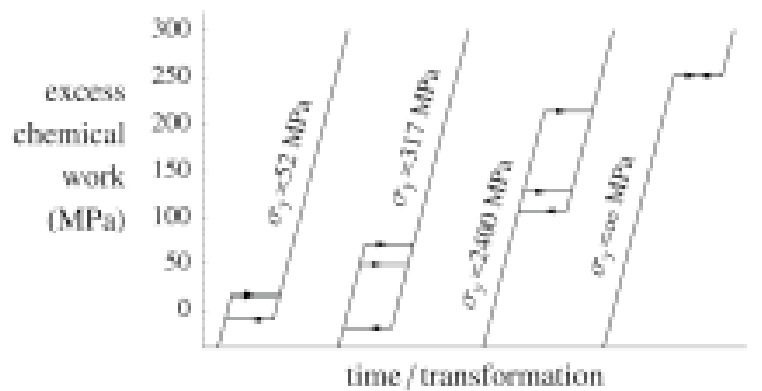

Figure 14: Schematic hysteresis curves using finite-element calculations of the excess chemical work of transformation defined by equations 5 and 6 for several different flow stresses. Both the initial hysteresis (outer loops) and the steady-state hysteresis (lower loops) are shown.

\begin{tabular}{|c|c|c|}
\hline & \multicolumn{2}{|c|}{ Hysteresis $\left(\mathrm{MPa}^{*}\right)$} \\
\hline & First Cycle & Steady State \\
\hline \multicolumn{3}{|l|}{ FEM (finite strain calculation) } \\
\hline Simple Fluid $\left(\square_{\mathrm{y}}=0 \mathrm{MPa}\right)$ & 0.0 & 0.0 \\
\hline Elastic + Plastic $\left(\square_{\mathrm{y}}=52 \mathrm{MPa}\right)$ & 27.6 & 23.1 \\
\hline Elastic + Plastic $\left(\square_{\mathrm{y}}=317 \mathrm{MPa}\right)$ & 89.4 & 68.0 \\
\hline Elastic + Plastic $\left(\square_{\mathrm{y}}=2400 \mathrm{MPa}\right)$ & 106 & 20.7 \\
\hline Pure Elastic $\left(\square_{\mathrm{y}}=\square \mathrm{MPa}\right)$ & 0.0 & 0.0 \\
\hline
\end{tabular}

Experiment (excess chemical work)

$\begin{array}{rr}\text { Flanagan \& Park [29] } & 46.2 \\ \text { Guthrie [43] } & 79.3\end{array}$

Table 2: Results of the hysteresis during PdH growth and dissolution predicted from the finite-element model with two sets of experimental measurements (Flanagan and Park [29] and Guthrie [43]). The hysteresis is reported in units of "excess chemical work" determined from equations 7 and 8 .

solution was on the upper side of curve, where the flow stress approaches the ideal shear strength of the material [25].

The present elastic-plastic analysis leads one to a different conclusion. If the flow stress is assumed to be near the ideal strength of the material, our modeling results (Table 2 ) show that the initial hysteresis should be very high ( $\sim 100 \mathrm{MPa})$, significantly larger than what is experimentally observed (45-80 MPa). In subsequent cycles, the elasticplastic model predicts a hysteresis of $\sim 20 \mathrm{MPa}$, which is now significantly below what is observed experimentally. However, if we assume that the flow stress is closer to the macroscopically observed yield stresses for palladium, the predicted difference between the first and subsequent cycles will be much less. Because we know of no experimental evidence for such a dramatic reduction in hysteresis after an initial cycle, we believe that it 
is most appropriate to use the lower strength solution of the elastic-plastic model presented in this paper. Linear interpolation then suggests that the experimental data can be fit reasonably well in a steady-state elastic-perfectly plastic hysteresis model with an effective flow stress of $\sim 290 \mathrm{MPa}$. Our modeling also either suggests that another explanation is needed for the reduction in hysteresis seen in PdH systems subject to significant radiation damage or that the types of continuum solutions used both here and by Wolfer and Guthrie are insufficient to capture all of the details of metal hydride hysteresis. One possibility is that helium bubbles formed during the radiation damage have a more complex effect on the transformation than simply raising the effective flow stress of the matrix. A more complete microstructural model may be needed to analyze the interaction between growing hydride particles and helium bubbles in the matrix. Eventually, tools such as dislocation dynamics or molecular dynamics could provide additional insights into the full complexity of metal-hydride growth and dissolution.

\section{Phase-field model}

Figure 15 shows the variation in total elastic energy and its derivative, the incremental transformation work for a periodic cubic array of hydride precipitates, as a function of the total volume fraction of hydride. To begin to analyze the effects of precipitate distribution and interactions on the transformation, two additional periodic simulations were run, using random nucleation at two different rates. Figure 16 shows three snapshots of the microstructural evolution for these simulations, and Figure 17 shows that nucleation rate has little effect on the incremental work of transformation.

In retrospect, it is unsurprising that nucleation rate has little effect, as there is an analytical solution for the strain energy of a system where the transformation produces pure dilatational misfit, the two-phase mixture is coherent, and the system is elastically
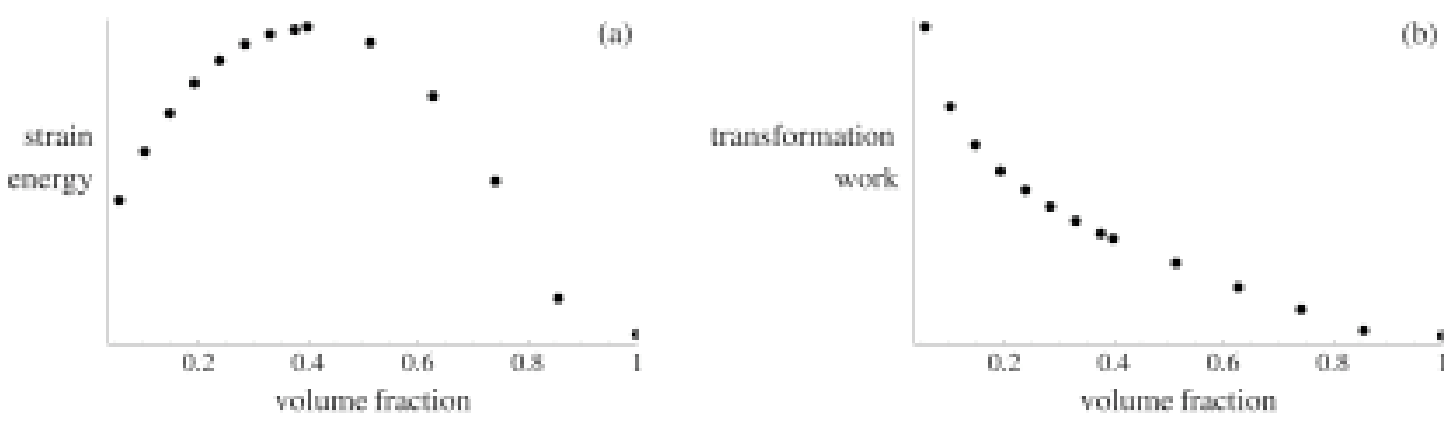

Figure 15: Phase-field microelasticity solution of a) elastic energy and b) incremental work of transformation as a function of hydride volume fraction for a periodic array of hydride precipitates in a perfectly elastic matrix. 


\section{Slow}

Nucleation
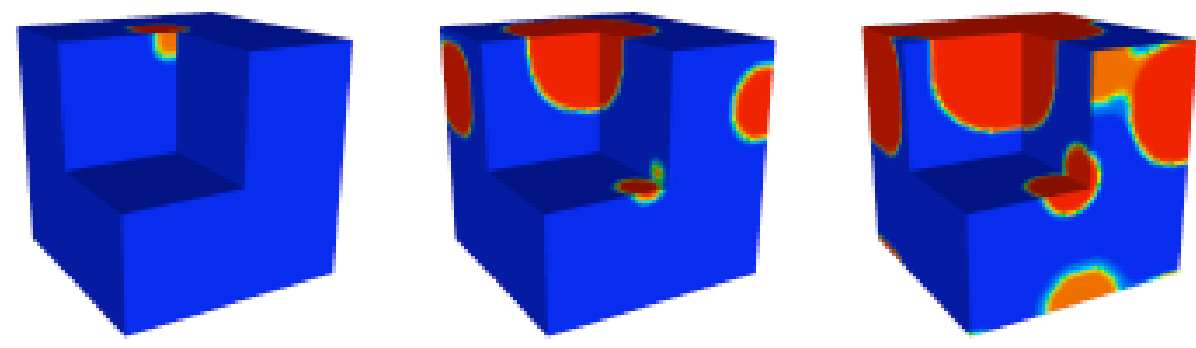

Fast

Nucleation
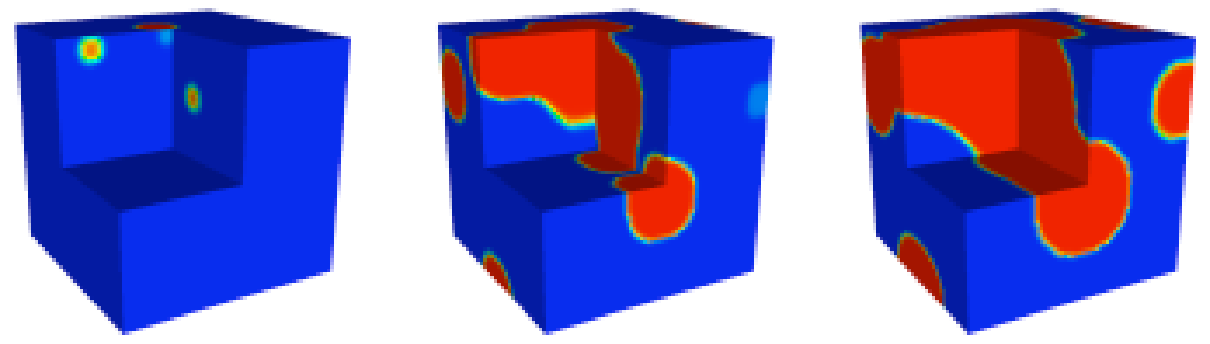

Figure 16: Illustration of microstructure evolution for two different nucleation rates. Each vertical pair of images has the same volume fraction of hydride.

isotropic, elastically homogeneous and macroscopically homogeneous [42]. Under these conditions, the strain energy $E$ and incremental work of transformation $W$ do not depend on the shape and mutual location of precipitates as long as the precipitates are distributed in a macroscopically homogeneous fashion:

$$
\begin{aligned}
& E^{\text {elastic }}=\frac{V}{2} \square \square \frac{1+\square}{1 \square \square} \square(1 \square \square), \text { and } \\
& W^{\text {elastic }}=\frac{V}{2} \square \square \frac{1+\square}{1 \square \square}(1 \square 2 \square),
\end{aligned}
$$

where $V$ is the total volume, $\square$ is the shear modulus, $\square$ is the misfit strain, $\square$ is the Poisson ratio, and $\square$ is the volume fraction of the precipitates. The variation of energy with

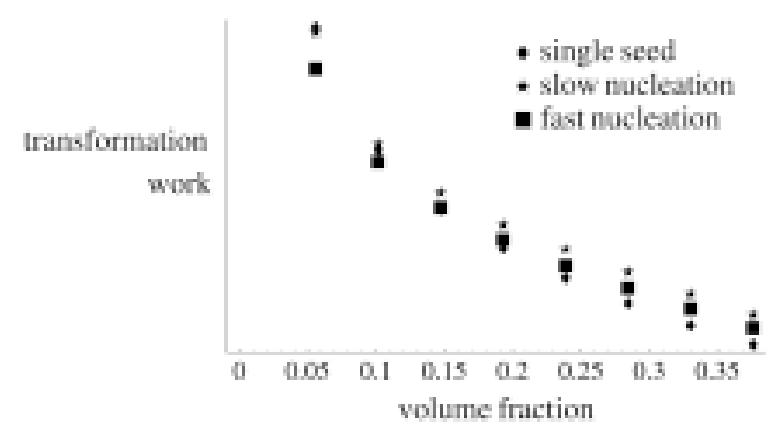

Figure 17: Phase-field solution of the incremental work of transformation as a function of hydride volume fraction for a variety of nucleation rates. 
volume fraction is parabolic, which is close to what we see in all the simulations.

Although our simulations actually used anisotropic elastic constants, a relatively high surface energy was chosen to maintain individual particles with an aspect ratio close to one. Our transformation strain was isotropic, and all three microstructures examined were essentially self-similar. (The nucleation rate was important only for the scale of the selfsimilar structures.) We believe that the effects of precipitate distribution and interactions will be more important in elastically anisotropic systems that include large shear components in the transformation. The effect of crystallographic texture will also be important in these systems.

The fact that the transformation work decreases with increasing volume fraction in both the simulations and in the analytical solution is the basis of the elastic hysteresis model of Schwartz and Khachaturyan [21] and has a curious implication: If the partial pressure of hydrogen in the gas phase were directly proportional to the excess chemical energy of the transformation, then the hydrogen overpressure required for further transformation should also decrease with increasing volume fraction. The reason that this reduction is not seen experimentally may be because the chemical potential of the hydrogen in the solid is a function of the changing mean stress in the metal and hydride phases [25].

\section{Future work}

In this work, the finite-element model did not include any microstructural evolution, and the phase-field model did not include any plastic dissipation. Ideally, a comprehensive model would include both. We did attempt to implement a plastic flow rule in the phasefield model, but because the transformation strain at each grid point in our periodic Fourier representation is homogeneous, it was impossible to obtain satisfactory solutions for the strain field around small hydride particles without increasing the grid densities to unreasonable large values. Conversely, although plasticity is easy to implement in a finiteelement framework, it is relatively difficult to adapt most commercially available finiteelement packages to model microstructural evolution. Several researchers have used finiteelement techniques to solve phase-field models, but these have been tailored specifically to examine the problems at hand, namely dendritic solidification [45] and electromigration driven void growth in electronic interconnects [46]. More recently, Idesman et al. have implemented a finite-element phase-field model of martensitic transformation [47], but they have not yet coupled dislocation plasticity to the model. In general, it can be difficult to balance the relative rates of transformation and dislocation plasticity, but for the case of hydride growth and dissolution, we can assume that plasticity happens more quickly 
than transformation because the rate of transformation is experimentally limited by the quantity of hydrogen that is introduced into the system.

\section{Modeling and observations of transformation crystallography and plasticity}

\section{Introduction}

The models for thermal hysteresis developed in the previous two sections assume that plastic dissipation is the dominant source for the hysteresis. Both models imply that there will be significant dislocation movement and multiplication near the interface between $\square$ and $\square \square$

The $\square \square[$ transformation is also somewhat unusual because it is isothermal and does not proceed to completion. (Typically $<30 \%$ G [is formed.) [48]. A reasonable hypothesis for the incomplete transformation to $\square[$ is based on the interaction between growing $\square \square$ nuclei or plates with $\square \square$ that was formed previously. Because $\square \square$ growth requires both local and long-range elastic and plastic rearrangements and since an array of high strength 口־plates will make these accommodations more difficult, growth of $\square$ will also become more difficult as the volume fraction of 0 Dincreases.

To explore the effects of $\square \square$ plate interactions numerically, Jin et al. [49] developed a phase-field model for the $\mathrm{D} \square \square$ transformation. (See the papers by Wang and Khachaturyan [28, 40] and by Jin et al. [28, 40] for more details.) This model was based on a transformation strain and habit plane (perpendicular to $<123>$ type directions in $\square$ ) predicted by Adler et al. [50] and experimentally observed by Zocco et al. [51]. The result of a single crystal simulation is shown in Figure 18. As expected, there are 24 variants predicted by the simulation. However, in most typical micrographs of a partially transformed Pu-Ga alloy (ex. Figure 18) only 3-4 variants are seen in any given grain.

The goal of the work in this section was two-fold. First, we aimed to determine whether there was any evidence of local plastic flow associated with the $\square$ to $\square \square$ transformation in order to validate our earlier modeling work of the hysteresis. Second, we wanted to understand the discrepancy between the modeled and observed microstructures in Figure 18.

\section{Experimental details}

We investigated a Pu-0.6 wt\% Ga alloy using optical microscopy and transmission electron microscopy (TEM). The alloy was prepared by induction heating and was approximately two years old. After casting, the material was usually annealed for at 425 $440^{\circ} \mathrm{C}$ to homogenize the $\mathrm{Ga}$ distribution. $\square \square$ was formed by quenching to either $-120^{\circ} \mathrm{C}$ or $-155^{\circ} \mathrm{C}$, which were in the upper and lower "c-curves" respectively. Optical speci- 

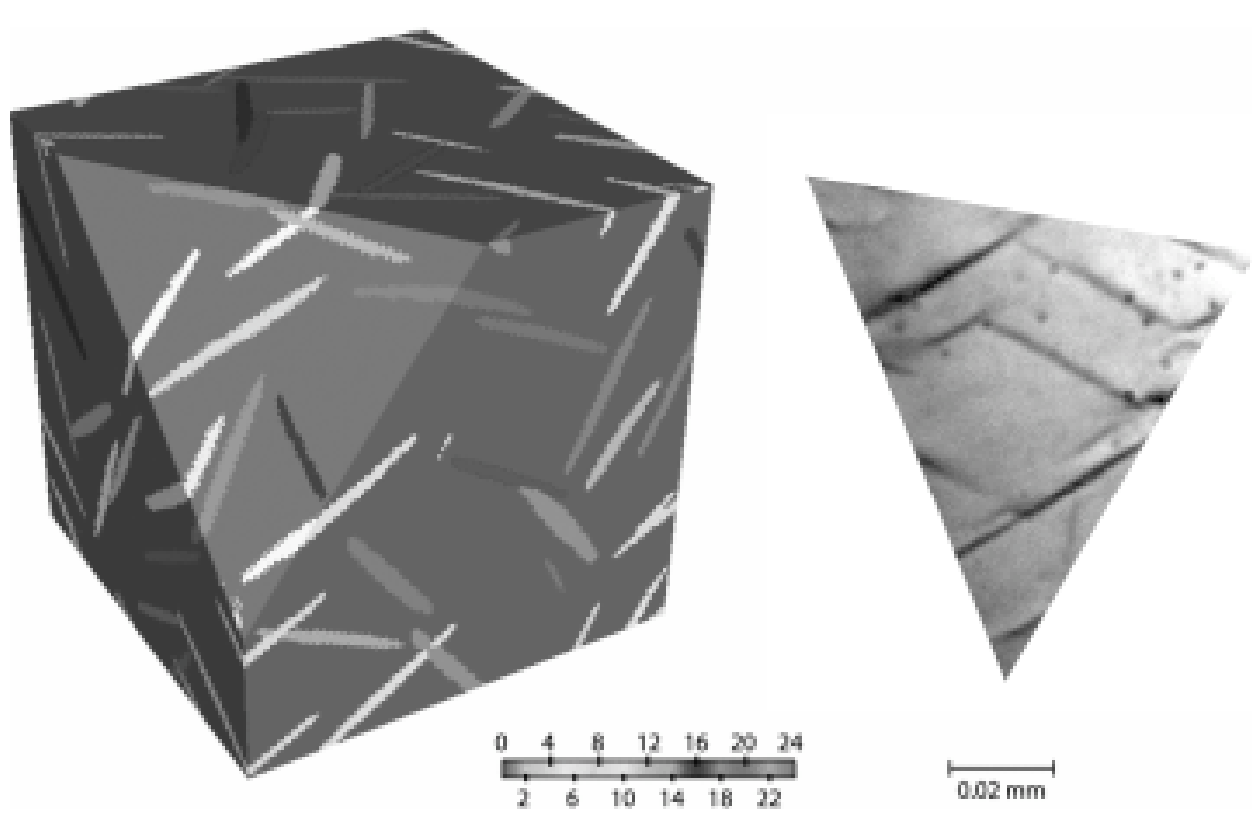

Figure 18: The cube on the left illustrates results of a three dimensional simulation of the $\square$ to $\square \square$ transformation in plutonium. The $\square$ phase matrix is medium grey. Each of the 24 crystallographically distinct $\square$ variants is shaded uniquely. The image on the right is an optical micrograph of a similar structure observed experimentally.

mens were mechanically polished and then lightly etched chemically. Samples were prepared for TEM by electropolishing $3 \mathrm{~mm}$ diameter discs, $150 \mu \mathrm{m}$ thick, to electron transparency using a Fischione Instruments electropolishing system. The thinning process was performed in an inert atmosphere glove box and the samples were transferred under vacuum to the TEM using a vacuum transfer specimen holder. The TEM work was performed on a FEI CM300FEG operating at $300 \mathrm{KeV}$ with a double tilt specimen holder. Additional details of the TEM specimen preparation and the electron microscope have been described by Wall et al. [52].

\section{Observations of plasticity}

In an as-received $\mathrm{Pu}-\mathrm{Ga}$ specimen quenched to $-120^{\circ} \mathrm{C}$ for 10 hours, dislocation density measurements were made with a line-intercept technique at 18 locations in the foil: 16 near $\square[$ plates and 2 in regions of $\square$ well removed from $\square \square$ plates. The average density near the $\square \square$ plates was $1.6 \square 10^{11}$ dislocations/cc. In isolated $\square$ the density was $2.5 \square 10^{10}$ dislocations/cc, a factor of 6 lower. Figure 19 shows two typical micrographs that were used for this analysis. The difference in dislocation density is apparent. In addition, Figure 19b shows the dislocation density near the dislocation tip is apparently higher than the density on the flank. 


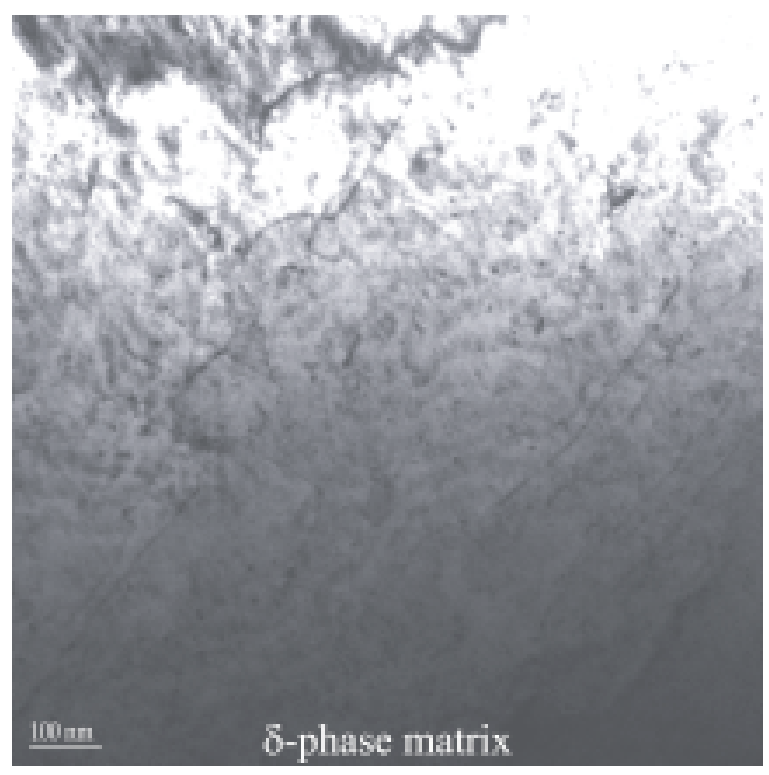

(a)

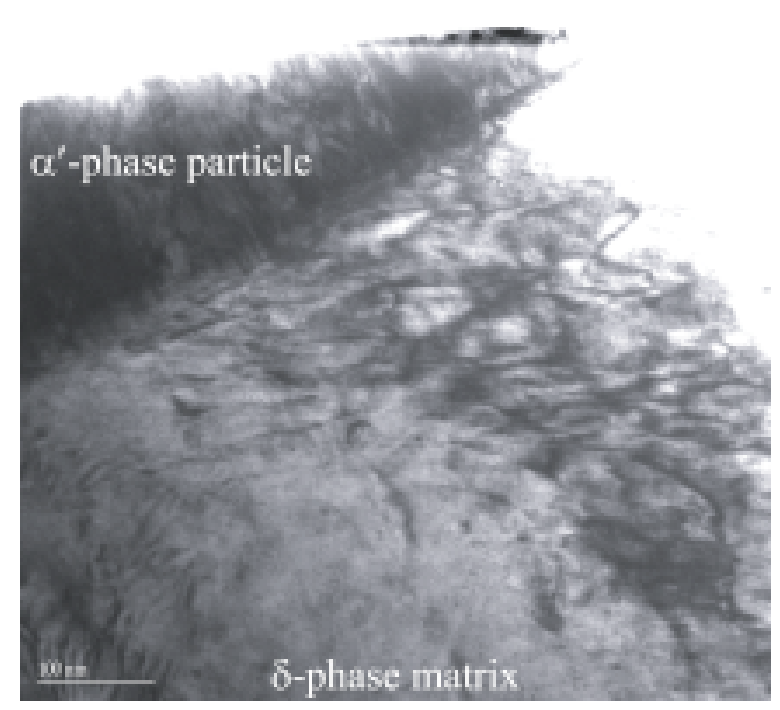

(b)

Figure 19: a) Transmission electron micrograph showing the background dislocation density in regions of $\square$ well removed from $\square \square$ plates. b) Micrograph illustrating the increase of dislocation density near the tip of an $\mathrm{CDplate.}$
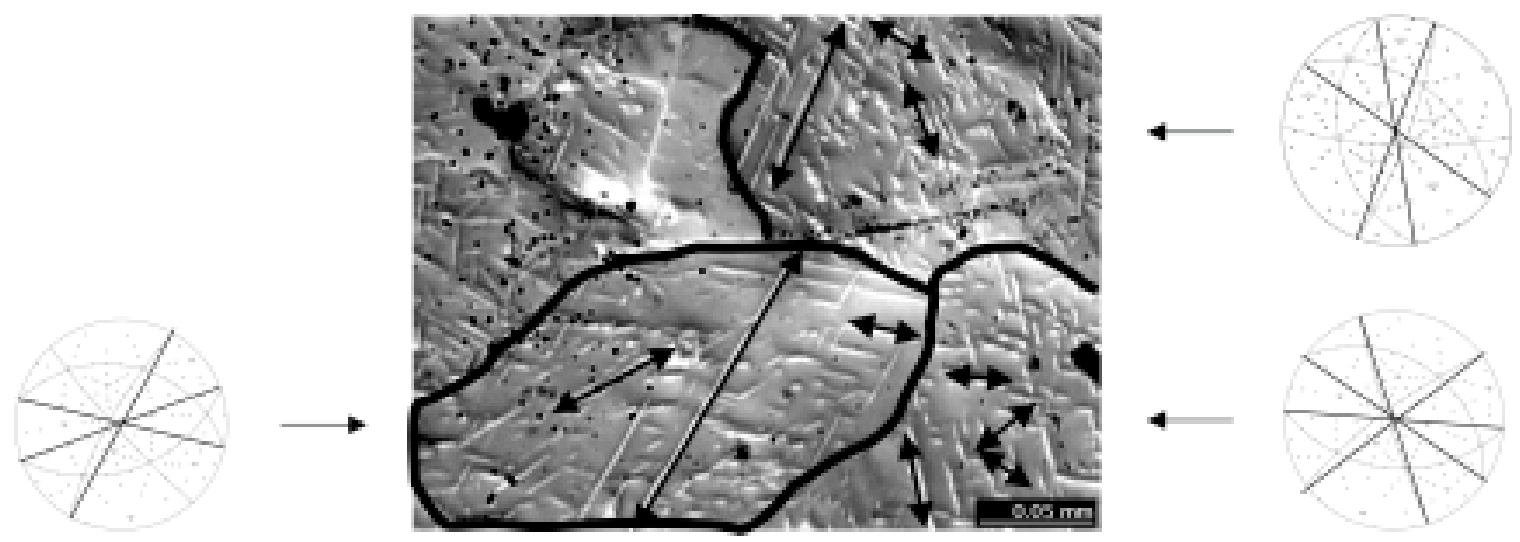

Figure 20: Optical micrograph of a partially transformed Pu-Ga alloy. The $\square$ appears dark grey and the $\square$ light grey. (Dark splotches are artifacts from polishing and image processing.) Grain boundaries and habit plane traces have been highlighted with black. Stereographic projections of inverse trace analyses are at the left and right. In these projections, the traces perpendicular to $<111>$ directions are shown with bold lines. 


\section{Habit plane determination \\ Optical microscopy}

Many tens of optical micrographs of dual phase $[$ plus $\quad[$ have been examined, and in the vast majority of cases, only three or four unique trace directions were observed. Figure 20 shows a typical optical micrograph of a specimen annealed at $425^{\circ} \mathrm{C}$ for 7 days then quenched to $-120^{\circ} \mathrm{C}$ for 6 hours. (We also observed a limited number of unique trace directions in specimens annealed for $>24$ hours at $450^{\circ} \mathrm{C}$, and so do not believe that inhomogeneities in the Ga distribution have any significant effect on the number of trace directions that can be observed.) Three grains were analyzed in detail. In two of the grains, three unique traces are seen. In the third grain, four unique traces are seen. Because these traces are generated by the intersection of the $\mathrm{CDplates}$ with the plane of the surface, it is not possible to determine the habit plane directly. However, with inverse trace analysis, it is possible to test whether the observed habit plane traces are consistent with any given habit plane orientation. Results of inverse trace analysis for three grains are shown in Figure 20 to the left and to the right of the micrograph. In all three cases, it was possible to choose a trial orientation in which the observed traces were all perpendicular to a $<111>$ direction.

\section{Transmission electron microscopy (TEM)}

In addition to providing high-resolution images of the morphology of D. TEM also directly provides lattice orientation information. Because of the thinness of the specimen foils, the imaged D[plates are actually projections of thin, needle-like cross sections of larger plates, and it is difficult to directly determine the habit plane from a single image. As in the optical micrography results, the vast majority of $\square$ grains contained $\square \square$ with only three or four unique trace directions. Figure 21 shows an image of a specimen annealed at $440^{\circ} \mathrm{C}$ for 8 hours then quenched to $-155^{\circ} \mathrm{C}$ for 10 hours. In this image, as in many others, the $\mathrm{CD}$ traces were perpendicular to $<111>$ directions as determined by electron diffraction.

Although it is not possible to determine the orientation of an $\mathrm{QD}$ needle from a single TEM micrograph, two images taken along different crystallographic directions are sufficient, as long as the axis of rotation between the directions is not particularly close to the orientation of the needle. For redundancy, and to provide an estimate of experimental error, images along three different crystallographic orientations were used to determine the orientations of three 0 Dneedles in two different grains. The orientations of these needles with respect to the fcc $\square$ matrix are shown in Figure 22a. In the cubic unit triangle, the orientations of the two needles from a single grain are very close to each other, which implies that they share a common habit plane. The experimental error is $\sim 5^{\circ}$. 


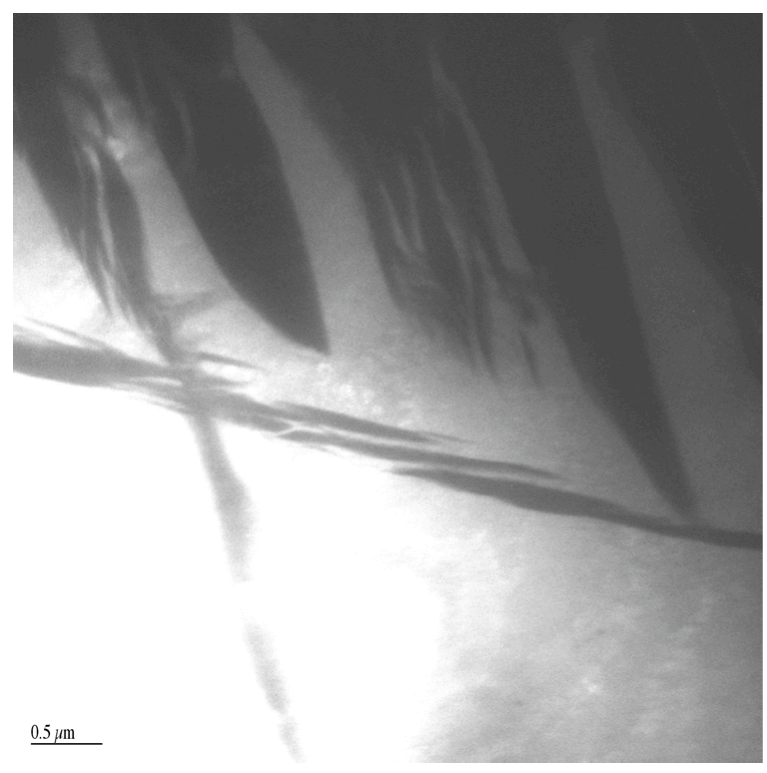

(a)

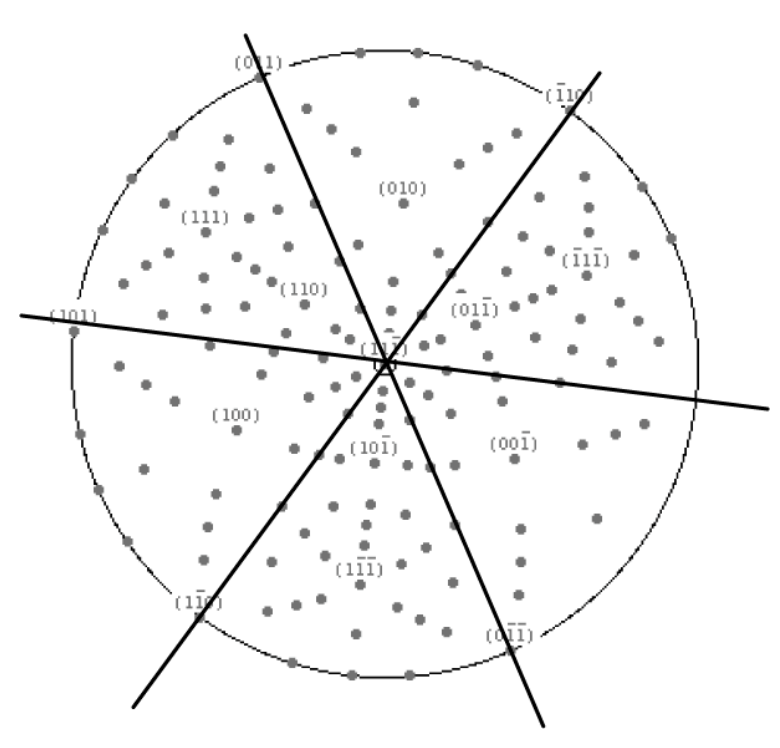

(b)

Figure 21: a) Transmission electron micrograph of $\square$ plates imaged along a $<111>$ direction in $\square$. b) Stereographic projection of the fcc $\square$ lattice as determined from the indexed diffraction pattern. In this projection, the traces perpendicular to $<111>$ directions are shown with bold lines.

If all the $\square[$ needles observed are assumed to share a common habit plane it is possible to determine solutions for this plane analytically, and the results of this analysis are shown in Figure 22b, which shows solutions clustered near the $\{112\}$ and $\{123\}$ orientations in $\square$. This is consistent with the predictions of Adler et al. [53] and the observations of Zocco et al. [51]. At the same time it is puzzling because symmetry suggests that

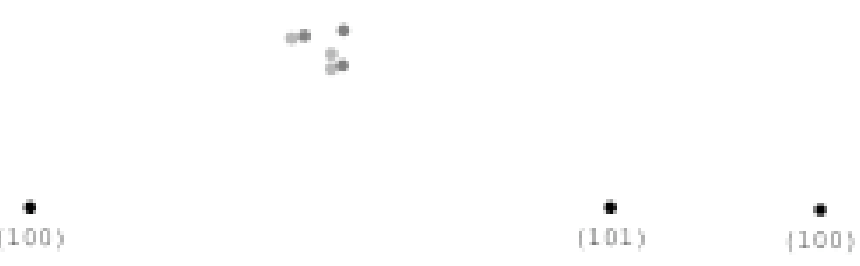

(a)

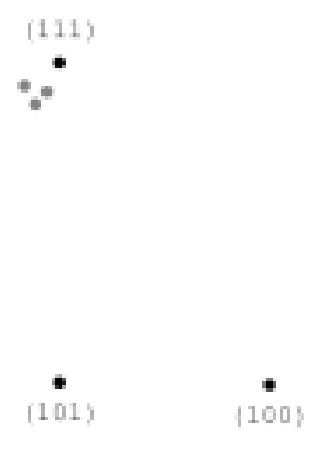

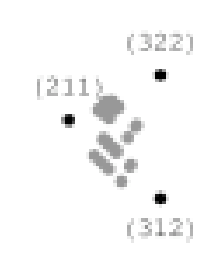

(b)

Figure 22: a) Orientations (in grey) of three $\square[$ needles determined from TEM trace analysis and plotted in the cubic unit crystallographic triangle of the fcc $\square$ matrix. b) Estimation of the habit plane of the needles (also in grey), assuming that they all share a common habit plane orientation. 
(010)

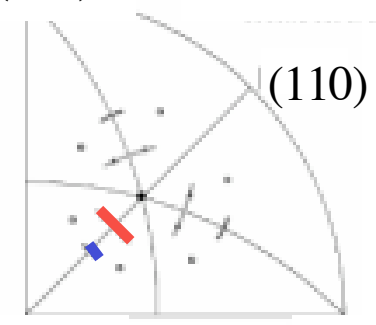

(001)
(100)

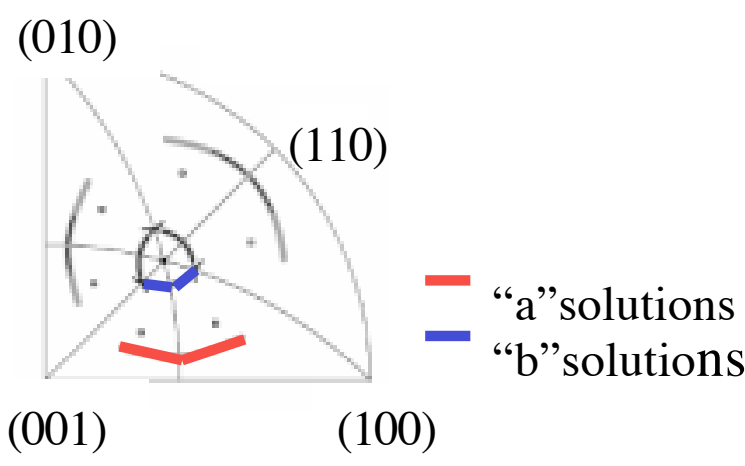

b)

Figure 23. Solutions for the habit plane of polytwinned martensite plates of 0 a) Solutions assuming a single shear correspondence between the fcc $\square$ lattice and the hcplike $\mathrm{C}$ lattice. b) Solutions assuming a double shear correspondence. The solutions in a) are close to $\{112\}$ or $\{123\}$. Some of the solutions in b) are much closer to $\{111\}$.

growth of $\mathrm{CD}$ on any of the 12 crystallographically unique $\{112\}$ planes or 24 distinct $\{123\}$ planes should be equally probable. However, in reality, we rarely see evidence of प[growth on more than three or four unique planes in a given grain.

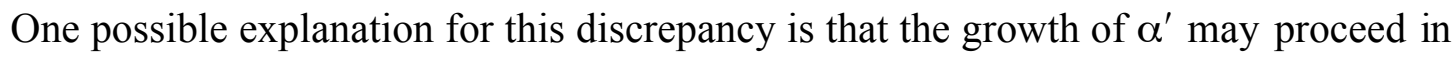
a highly cooperative manner, and that once a single plate of $\square$ forms in a given grain, it will bias the growth of future plates, such that only 3-4 variants are allowed. However, it would be unwise to make this conclusion based on the observations of three $\mathrm{C} \square$ needles, so further TEM analysis is planned.

\section{Crystallographic modeling}

In a contract placed with Rutgers University, Professor Armen Khachaturyan and his coworkers have been responsible for crystallographic modeling of the $\square$ to $\square[$ transformation. They have repeated the analysis first performed by Adler et al. [50], and when they use the same lattice correspondence (a single shear correspondence) used by Adler et al., they find a habit plane for $\square \square$ that is close to $\{112\}$ and $\{123\}$ (Figure 23a). However, if they use a double shear correspondence, which should result in a lower total elastic energy, they find a habit plane solution that is much closer to $\{111\}$ (Figure 23b). We also note that neither Adler's or Khachaturyan's model includes elastic energy terms, which could result in habit planes closer to low index planes such as $\{111\}$. In addition, both models do predict internal twinning in the martensite plates, which also has been observed experimentally [51,54]. 


\section{Structural studies of a Pu-Ga alloy using EXAFS}

Extended x-ray absorption fine structure spectroscopy (EXAFS) was used to investigate the local atomic environment and vibrational properties of plutonium and gallium atoms in the $\square$ ' and $\square$ phases of a Pu-0.6 wt\% Ga alloy. One goal of this work was to understand where the $\mathrm{Ga}$ atoms sat in the monoclinic $\square$ ' and fcc $\square$ lattices. To investigate these

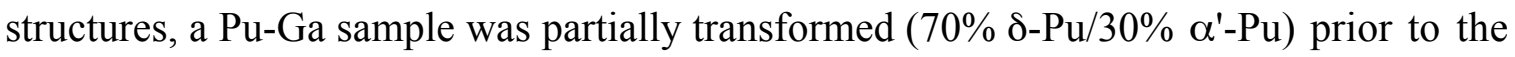
experiments. Ga $K$-edge EXAFS spectra suggested that the $\mathrm{Ga}$ is substitutional for $\mathrm{Pu}$ atoms in both the $\square$ '-Pu and the $\square-\mathrm{Pu}$ structures. Previous work showed that the $\square$ ' lattice has eight unique lattice sites [55], and comparison of the experimental EXAFS data with modeled EXAFS data indicated that the substitution of $\mathrm{Ga}$ atoms was random within these eight sites. The same partially transformed sample was re-examined with EXAFS after sitting at room temperature for eight months. The spectra did not change, which indicated that the diffusion of the $\mathrm{Ga}$ in $\square$ '-Pu was very slow at ambient temperatures. This EXAFS work was important in furthering our understanding of the structure and stability of Pu-Ga alloys.

\section{Other accomplishments}

\section{Scientific presentations and publications}

We have contributed 5 journal and conference papers and 13 oral or poster presentations to 6 different conferences. An additional paper is currently in preparation.

\section{Papers}

1. J. J. Haslam, M. A. Wall, D. L. Johnson, D. J. Mayhall, and A. J. Schwartz, "Phase transformation hysteresis in a plutonium alloy system: modeling the resistivity during the transformation," in MRS Proceedings: Electrically based microstructural characterization III, Vol. 699 (2002), p. 295. UCRL-JC-144283.

2. E. J. Nelson, K. J. M. Blobaum, M. A. Wall, P. G. Allen, A. J. Schwartz, and C. $\mathrm{H}$. Booth, "Local structure and vibrational properties of $\square$ '-Pu martensite in Gastabilized —-Pu," Phys. Rev. B., (2003) 67, 224206. UCRL-JC-1000752

3. C. R. Krenn, "Continuum modeling of transformation hysteresis in a metal hydride system.” Modelling Simul. Mater. Sci. Eng., accepted for publication (2003) UCRL-JC-151820.

4. K. J. M. Blobaum, C. R. Krenn, J. J. Haslam, M. A. Wall, and A.J. Schwartz, "'Burst-like' characteristics of the $\square \square$ ' phase transformation in Pu-Ga alloys," in MRS Proceedings: Actinides-Basic Science, Applications, and Technology, accepted for publication (2004). UCRL-CONF-200963

5. C. R. Krenn, M. A. Wall, and A. J. Schwartz, "Transformation crystallography and plasticity of the delta to alpha' transformation in plutonium alloys," in MRS Proceedings: Actinides-Basic Science, Applications, and Technology, accepted for publication (2004). UCRL-CONF-201578 
6. K. J. M. Blobaum, C. R. Krenn, J. J. Haslam, M. A. Wall, and A. J. Schwartz, "Investigating the $\square \square$ ' transformation in Pu-Ga alloys," to be submitted to Met. and Mat. Trans. A.

\section{Presentations}

1. J. J. Haslam, M. A. Wall, D. L. Johnson, D. J. Mayhall, and A. J. Schwartz, "Phase transformation hysteresis in a plutonium alloy system: modeling the resistivity during the transformation," MRS Fall Meeting, Boston, MA, Nov. 26-30, 2001. UCRL-JC-144283-ABS

2. K. Blobaum, J. Haslam, A. Brough, M. Wall, and A. Schwartz, "Investigating the $\square \square$ ' martensitic phase transformation in Pu-Ga alloys," Poster at The $2^{\text {nd }}$ International Workshop on Spin and Orbital Magnetism of Actinides, Berkeley, CA, October 13-15, 2002. UCRL-MI-149588

3. C. R. Krenn, B. Sadigh, A. J. Schwartz, and W. G. Wolfer, "Effects of local solute ordering and plasticity on the delta to alpha transformation in gallium-stabilized plutonium alloys," Poster at The $2^{\text {nd }}$ International Workshop on Orbital And Spin Magnetism of Actinides, Berkeley, CA, October 13-15, 2002. UCRL-JC-149837ABS

4. E. Nelson, K. Blobaum, M. Wall, P. Allen, and A. Schwartz, "Multi-scale structural study of the $\square \rightarrow \square$ ' transformation in a Pu-Ga alloy," Poster at The $2^{\text {nd }}$ International Workshop on Spin and Orbital Magnetism of Actinides, Berkeley, CA, October 13-15, 2002. UCRL-PRES-149687

5. J. J. Haslam, M. A. Wall, K. J. M. Blobaum, and A. J. Schwartz, "Investigation of differences in morphology and transformation mechanisms of alpha' formed from delta plutonium at low temperatures," TMS Spring Meeting, San Diego, CA, March 2-6, 2003. UCRL-JC-149061-ABS

6. C. R. Krenn, A. J. Schwartz, W. G. Wolfer, Y. M. Jin, and A. G. Khachaturyan, "Phase field modeling of metal hydride growth in a plastically deforming matrix," TMS Spring Meeting, San Diego, CA, March 2-6, 2003. UCRL-JC-149179-ABS

7. C. R. Krenn, B. Sadigh, A. J. Schwartz, and W. G. Wolfer, "Effects of plasticity and local solute ordering on the delta to alpha transformation in gallium-stabilized plutonium alloys," TMS Spring Meeting, San Diego, CA, March 2-6, 2003. UCRL-JC-149178-ABS

8. K. Blobaum, J. Haslam, A. Brough, M. Wall, and A. Schwartz, "Investigating the

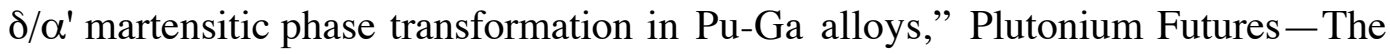
Science Conference, Albuquerque, NM, July 6-10, 2003. UCRL-PRES-149588

9. C. R. Krenn, B. Sadigh, A. J. Schwartz, and W. G. Wolfer, "Effects of local solute ordering and plasticity on the delta to alpha transformation in gallium stabilized plutonium alloys". Plutonium Futures - The Science Conference, Albuquerque, NM, July 6-10, 2003. UCRL-JC-151541

10. E. Nelson, K. Blobaum, M. Wall, P. Allen, and A. Schwartz, "Local structure and vibrational properties of (alpha)'-Pu martensite and Ga-stabilized (delta)-Pu," Poster at Plutonium Futures - The Science Conference, Albuquerque, NM, July 610, 2003. UCRL-JC-149837-EXT-ABS

11. C. R. Krenn, A. J. Schwartz, and W. G. Wolfer, "Continuum modeling of hysteresis during solid-state phase transformations" " $7^{\text {th }}$ US National Congress on Computational Mechanics, Albuquerque, NM, July 28-30, 2003. UCRL-JC-151820 
12. K. J. M. Blobaum, C. R. Krenn, J. J. Haslam, M. A. Wall, and A. J. Schwartz, "Investigating the QVD' phase transformation in Pu-Ga alloys," MRS Fall Meeting, Boston, MA, December 1-4, 2003. UCRL-PRES-200962

13. C. R. Krenn, M. A. Wall, and A. J. Schwartz, "Transformation crystallography and plasticity of the delta to alpha' transformation in plutonium alloys," MRS Fall Meeting, Boston, MA, December 1-4, 2003. UCRL-JC-143514-ABS

\section{Development of new scientific capabilities}

This project has brought a number of new scientific capabilities to LLNL. 1) We have obtained a phase field microelasticity computer code from Armen Khachaturyan at Rutgers University. This code can be used to calculate stresses and to model microstructural evolution in a wide variety of material systems. 2) We have developed the capability to analyze the elastic and plastic works of transformation of solid state phase transformations. 3) We have developed expertise in running differential scanning calorimetry measurements on actinide materials.

\section{Development of scientific manpower}

A final important benefit of this effort is the development of the scientific manpower base for future stockpile stewards. The challenging problems of performing research on actinide metals require a special level of training beyond what is available from institutions of higher learning. This initiative is establishing LLNL as one of a few worldwide centers-of-excellence in the science of Pu metals. It will thus provide the skills, technology, and personnel required to meet long-term strategic and tactical needs relevant to this scientifically interesting and challenging system. To date, our progress in this area has been significant. A post-doc and two term employees have entered into this plutonium science effort.

\section{Conclusions and future work}

\section{Resistivity modeling}

We followed the progress of the $\mathrm{V} \backslash \mathrm{\square}$ ' phase transformation in a $\mathrm{Pu}-\mathrm{Ga}$ alloy using fourpoint probe resistometry on a $2.8 \mathrm{~mm}$ diameter disc. Using finite-element modeling, we first determined that the four-point probe technique gave sufficient sensitivity and accuracy with this sample geometry. We then used finite-element methods to examine the effects of $\square$ ' particle orientation and arrangement within the $\square$ grains. Considerable anisotropy in the resistivity may occur depending on these factors. Therefore, we investigated the validity of the series and parallel models for estimating the amount of $\square$ ' present in a sample. It was determined that an average of these two models gave a good estimate of the amount of $\square$ ' in a simulated sample. The fraction of $\square$ ' predicted by the average of the parallel and series models was in good agreement with the amount of $\square$ ' calculated using 
an x-ray diffraction technique. Therefore, we concluded that resistometry data analyzed with the corrected series model gave an accurate measurement of the amount of $\square$ ' in a $\square$ matrix. This technique could also be applied to other materials with a two-phase microstructure.

\section{"Burst-like" characteristics of the $\square \square$ ' phase transformation}

The $\square$ ' $\leftrightarrow \square$ phase transformation in a $\mathrm{Pu}-0.6 \mathrm{wt} \%$ Ga alloy was investigated with differential scanning calorimetry and resistometry. Martensite start and austenite start temperatures of $-120^{\circ} \mathrm{C}$ and $35^{\circ} \mathrm{C}$, respectively, were established for this alloy. DSC and resistometry data were in excellent agreement on these temperatures.

Upon heating in the DSC, "spikes" were observed during the $\square$ ' $\rightarrow \square$ reversion; similarly, "steps" were observed in the resistometry trace. These "steps" and "spikes" were periodic with respect to temperature. Similar behavior was observed in DSC and dilatometry studies by other groups. For a given alloy, the period of these spikes and steps was independent of heating rate and characterization technique. No systematic variation with composition, microstructure, homogenization, impurity content, or other factors has been confirmed yet.

A single sample exhibited reproducible thermal cycling behavior as long as it was annealed at $375^{\circ} \mathrm{C}$ for 8 hours and then allowed to "rest" at room temperature for a minimum of 6 hours before the next thermal cycle. During this room temperature hold, radiation damage may have accumulated, providing nucleation sites for the martensitic transformation to $\square$ ' on cooling. Diffusional growth of small $\square$ nuclei may have also occurred during the room temperature hold. This effect appeared to saturate after approximately 6 hours.

\section{Continuum models of transformation hysteresis}

A simple analytic model for the marternsite start and austenite reversion temperatures agrees closely with the available experimental data for Pu-Ga alloys.

An elastic/perfectly plastic finite-element model of hysteresis in the $\mathrm{Pd} / \mathrm{PdH}$ system gives reasonable agreement to experimental observations if an effective flow stress of 280 $\mathrm{MPa}$ is assumed. This value is consistent with experimental measurements of flow stress in $\mathrm{PdH}$.

The finite-element model predicts that hysteresis will decrease as hydriding and dehydriding continues. This prediction is consistent with experimental data [44].

However, this finite-element model does not offer a reasonable explanation of the reduction of hysteresis in aged $\mathrm{PdT}$ systems that are subject to significant radiation damage [25]. 
These finite-element techniques are currently being used to calculate the work of transformation in Pu-Ga alloys.

Phase-field and analytical elasticity modeling suggests that there will be little effect of nucleation rate on hysteresis.

A more general microstructural model that includes both plastic dissipation and microstructural evolution would be useful for modeling metal hydrides and other systems with large transformation volume changes. A general-purpose finite-element field could be used for this purpose.

\section{Modeling and observations of crystallography, plasticity and structure}

We have used transmission and optical microscopy to improve our understanding of the $\square$ to $[\square$ transformation in Pu-Ga alloys. We have shown evidence of significant plastic deformation associated with the transformation. Although a small number of TEM measurements suggests that the habit plane of $\square$ is near $\{112\}$ or $\{123\}$, we still have no definitive explanation for the small $(\sim 4)$ number of variants that are typically observed. Further microscopy and crystallographic analysis is planned to resolve these questions.

Crystallographic modeling of the $\square$ to $\square \square$ transformation revealed that the habit plane

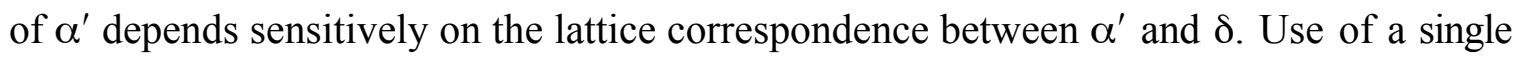
shear correspondence reproduces the results of Adler et al. [50] (a habit plane near $\{112\}$ or $\{123\})$, but the use of a double shear correspondence results in a habit plane solution that is much closer to $\{111\}$.

Extended x-ray absorption fine structure spectroscopy (EXAFS) was used to investigate the local atomic environment and the vibrational properties of plutonium and gallium atoms in the $\square^{\prime}$ and $\square$ phases of a Pu- $0.6 \mathrm{wt} \% \mathrm{Ga}$ alloy. EXAFS spectra suggested that the $\mathrm{Ga}$ is substitutional for $\mathrm{Pu}$ atoms in both the $\mathrm{C}^{\prime}-\mathrm{Pu}$ and the $\mathrm{C}-\mathrm{Pu}$ structures. Preliminary analysis did not reveal any evidence for preferential ordering of $\mathrm{Ga}$ in the alpha lattice.

\section{Other accomplishments}

To communicate the results obtained in the course of this LDRD project, we have presented 13 talks or posters at 6 scientific conferences and published 5 conference and journal papers. We also have developed the capabilities for differential scanning calorimetry, phase field modeling, and elasto-plastic analysis of phase transformations. Finally, this project has been partially responsible for the recruitment of two term employees and one post doc to the plutonium science program at LLNL. 


\section{References}

1. P. H. Adler, Metall. Trans. A 22A, 2237 (1991).

2. L. F. Timofeeva, JOM-J. Min. Met. Mat. 55, 51 (2003).

3. S. S. Hecker, D. R. Harbur, and T. G. Zocco, Progress in Mat. Sci. 49, 429 (2004).

4. J. J. Haslam, M. A. Wall, D. L. Johnson, D. J. Mayhall, and A. J. Schwartz, in Electrically Based Microstructural Characterization III, edited by R. A. Gerhardt, A. P. Washabaugh, M.A. Alim and G. M. Choi, (Mater. Res. Soc. Proc. 699, Pittsburgh, PA, 2002) pp. 295-300.

5. K. J. M. Blobaum, C. R. Krenn, J. J. Haslam, M. A. Wall, and A.J. Schwartz, in Actinides-Basic Science, Applications, and Technology, edited by L. Soderholm, J. Joyce, M. F. Nicol, D. Shuh, and J. G. Tobin, (Mater. Res. Soc. Proc. 802, Pittsburgh, PA, 2004) in press.

6. C. R. Krenn, Modelling Simul. Mater. Sci. Eng. accepted for publication (2003).

7. C. R. Krenn, M. A. Wall, and A. J. Schwartz, in Actinides-Basic Science, Applications, and Technology, edited by L. Soderholm, J. Joyce, M. F. Nicol, D. Shuh, and J. G. Tobin, (Mater. Res. Soc. Proc. 802, Pittsburgh, PA, 2004) in press.

8. E. J. Nelson, K. J. M. Blobaum, M. A. Wall, P. G. Allen, A. J. Schwartz, and C. H. Booth, Phys. Rev. B 67, 224206 (2003).

9. R. B. Gibney and T. A. Sandenaw, "Electrical resistivity of plutonium metal and of gallium-plutonium alloys over the temperature range of $26^{\circ} \mathrm{k}$ to $\sim 773^{\circ} \mathrm{k}$," Los Alamos Report No. LA-1883 (1954).

10. J. Joel, C. Roux, and M. Rapin, J. Nucl. Mater. 40, 297 (1971).

11. R. J. Jackson and R. J. Pinkney, Metallography 1, 387 (1969).

12. J. N. Mitchell, M. Stan, D. S. Schwartz, and C. J. Boehlert, Metall. Mater. Trans. A accepted for publication (2003).

13. T. F. J. Pijpers, V. B. F. Mathot, B. Goderis, R. L. Scherrenberg, and E. W. van der Vegte, Macromolecules 35, 3601 (2002).

14. S. Kitching, P. G. Planterose, and D. C. Gill, in Phase Transformation in DeltaStabilized Plutonium, Albuquerque, NM, 2003 (American Institute of Physics), p. 79.

15. M. J. Fluss, B. D. Wirth, M. Wall, T. E. Felter, M. J. Caturla, A. Kubota, and T. Diaz de la Rubia, J. Alloys and Compounds, in press (2004).

16. S. S. Hecker and L. F. Timofeeva, Los Alamos Science 26, 244 (2000).

17. B. Sadigh and W. G. Wolfer, in preparation.

18. H. R. Gardner, in Plutonium Handbook: A Guide to theTechnology; Vol. 1, edited by O. J. Wick (Gordon and Breach, New York, 1967), p. 59.

19. S. S. Hecker, Progress in Mat. Sci., in press (2002).

20. B. J. Makenas and H. K. Birnbaum, Acta Metall. 28, 979 (1980).

21. R. B. Schwarz and A. G. Khachaturyan, Phys. Rev. Lett. 74, 2523 (1995).

22. H. K. Birnbaum, M. L. Grossbeck, and M. Amano, J. Less-Common Metals 49, 357 (1976).

23. M. P. Puls, Acta Metall. 32, 1259 (1984).

24. S. Qian and D. O. Northwood, Int. J. Hydrogen Energy 15, 649 (1990). 
25. W. G. Wolfer and S. E. Guthrie, in Hydrogen effects on material behavior and corrosion deformation interactions, edited by N. R. Moody, A. W. Thompson, R. E. Ricker, G. S. Was, and R. H. Jones (TMS, 2003), p. B03.

26. B. W. Leitch and S.-Q. Shi, Modelling Simul. Mater. Sci. Eng. 4, 281 (1996).

27. B. W. Leitch and M. P. Puls, Met. Trans. 23A, 797 (1992).

28. Y. Wang and A. G. Khachaturyan, Acta Mat. 45, 759 (1997).

29. T. B. Flanagan and C.-N. Park, Mater. Sci. Forum 31, 297 (1988).

30. E. Ho, H. A. Goldberg, G. C. Weatherly, and F. D. Manchester, Acta Metall. 27, 841 (1979).

31. E. Wicke and J. Blaurock, J. Less-Common Metals 130, 351 (1987).

32. D. K. Hsu and R. G. Leisure, Phys. Rev. B 20, 1339 (1979).

33. L. A. Nygren and R. G. Leisure, Phys. Rev. B 37, 6482 (1988).

34. R. Feenstra, R. Griessen, and D. G. de Groot, J. Phys. F: Met. Phys. 16, 1933 (1986).

35. S. H. Goods and S. E. Guthrie, Scripta Metall. Mater. 26, 561 (1992).

36. C. R. Krenn, unpublished data (2002).

37. ABAQUS Software, Hibbitt, Karlsson, and Sorensen, Inc., Pawtucket, RI.

38. J. K. Lee, Y. Y. Earmme, H. I. Aaronson, and K. C. Russell, Met. Trans. A 11, 1837 (1980).

39. R. Kobayashi, Physica D 63, 410 (1993).

40. Y. M. Jin, A. Artemev, and A. G. Khachaturyan, Acta Mat. 49, 2309 (2001).

41. A. G. Khachaturyan and G. A. Shatalov, Sov. Phys. JETP 29, 557 (1969).

42. A. G. Khachaturyan, in Theory of structural transformations in solids (John Wiley and Sons, New York, 1983).

43. S. E. Guthrie, unpublished data.

44. B. Lambert and F. Gates, Proc. Roy. Soc. A 108, 456 (1925).

45. J.-H. Jeong, N. Goldenfeld, and J. A. Dantzig, Phys. Rev. E 64, 041602/1 (2001).

46. D. N. Bhate, A. F. Bower, and A. Kumar, J. Mech. Phys. Solids 50, 2057 (2002).

47. A. V. Idesman, V. I. Levitas, and D. L. Preston, in Dislocations, Plasticity and Metal Forming (Neat Press, Baltimore, MD, 2003), p. 130.

48. J. T. Orme, M. E. Faiers, and B. J. Ward, in Plutonium 1975 and Other Actinides, edited by H. Blank and R. Lindner (North-Holland Publishing Company, Amsterdam, 1975), p. 761.

49. Y. M. Jin, Y. U. Wang, and A. G. Khachaturyan, unpublished research (2002).

50. P. H. Adler, G. B. Olson, and D. S. Margolies, Acta metall. 34, 2053 (1986).

51. T. G. Zocco, M. F. Stevens, P. H. Adler, R. I. Sheldon, and G. B. Olson, Acta Metall. Mater. 38, 2275 (1990).

52. M. A. Wall, A. J. Schwartz, and M. J. Fluss, "Sample preparation for transmission electron microscopy characterization of Pu alloys," LLNL Report No. UCRL-ID141746 (2000).

53. P. H. Adler and G. B. Olson, Metall. Trans. A 19, 2705 (1988).

54. M. A. Wall, C. R. Krenn, and A. J. Schwartz, unpublished research (2003).

55. W. H. Zachariasen and F. H. Ellinger, Acta Cryst. 16, 777 (1963). 